\title{
SECHIBA, a New Set of Parameterizations of the Hydrologic Exchanges at the Lamd- Atmosphere Interface within the LMD Atmospheric General Circulation Model
}

\author{
NATHALIE I. DUCOUDRE* \\ Laboratoire de Météorologie Dynamique (CNRS), Paris, France \\ Katia LaVAL \\ Laboratoire de Météorologie Dynamique (CNRS), Paris, France \\ ALAIN PERRIER \\ Institut National Agronomique de Paris-Grignon, Grignon-Thiverval, France
}

(Manuscript received 8 March 1991, in final form 3 March 1992)

ABSTRACT

\begin{abstract}
A simple parameterization of the hydrologic exchanges between the soil-vegetation system and the atmosphere (SECHIBA) has been developed for use within atmospheric general circulation models (AGCM).

For each grid box of the model, eight land surface types (bare soil plus seven vegetation classes) are defined, each of them covering a fractional area of the grid box and allowed to be found simultaneously. Over each of these covers the transfers are computed: evaporation from soil, transpiration from plants through a resistance defined by the concepts of stomatal resistance and architectural resistance, and interception loss from the water reservoir over the canopy. These fluxes are then averaged over the grid box to derive the total amount of water vapor that is transferred to the first atmospheric level of the AGCM. Parameterization of soil water allows for the moistening of an upper layer, of variable depth, during a rainfall event.

This new scheme is quite simple and requires prescription of a restricted number of parameters: seven for each class of vegetation and four for the soil. Nevertheless, it is demonstrated that the latent heat fluxes it simulates are quite comparable to the ones simulated by the Biosphere-Atmosphere Transfer Scheme or calculated by Shuttleworth over the tropical rainforest of the Reserva Ducke (Amazon), with no tuning involved.
\end{abstract}

\section{耳. Introduction}

Sensitivity studies performed with atmospheric general circulation models (AGCMs) have shown that land surface processes influence the transfers between land surface and the atmosphere, as reviewed by Mintz (1984). Ten years ago, Mintz (1982) proposed to introduce the vegetation properties that undergo seasonal variations into AGCMs for climate studies in order to realistically represent the water budget of the atmosphere. Schemes that calculate transpiration from plants, interception loss and storage of the canopy have been designed (Deardorff 1978; Dickinson 1984; Sellers et al. 1986) to be used in AGCMs. Those models depend on many parameters that need to be calibrated

* Present affiliation: Laboratoire de Modélisation du Climat et de l'Environnement (CEA), France.

Corresponding author address: Dr. Nathalie I. Ducoudré, Laboratoire de Modélisation du Climat et de l'Environnement, D.S.M./ Orme des Merisiers Bát-709, C.E. Saclay, 91191 Gif-sur-Yvette Cédex, France. to enhance the model performance (Sellers et al. 1989). They have been introduced in AGCMs (Sato et al. 1989). Some deforestation studies have been performed where tropical forest was replaced by grassland. The first of these was that of Dickinson and Henderson-Sellers (1988). All these models treat the vegetation layer in a grid box as a "big leaf" with mean value of parameters such as surface resistance, for example. The difficulty of using a big leaf model in a square of the order of $10^{4} \mathrm{~km}^{2}$ or more has been stressed by McNaughton (1987) or Avissar and Verstraete (1990).

Another point that seems important to consider in AGCMs is the subgrid spatial variability of precipitation and soil moisture (Entekhabi and Eagleson 1989). Attempts to introduce those in AGCMs are under way (Wood et al. 1992).

It is not obvious how to define the level of complexity AGCMs must adopt when they include soil and vegetation in their simulation. For example, the Simple Biosphere model (Sellers et al. 1986) has recently been simplified, without loosing accuracy (Xue et al. 1991), by reducing the number of prescribed parameters it requires from 44 to 21 . More sensitivity experiments 
are needed to find out what are the most important processes with respect to the interactions between soil, vegetation, and atmosphere that must be represented within these new schemes.

In this context we have defined a scheme of the biosphere-atmosphere interface to be used within the LMD AGCM. The focus is on the hydrologic exchanges between soil, vegetation, and the atmosphere. It introduces the concept of surface resistance for transpiration and represents interception loss and storage of the foliage. These water exchanges are modeled for eight types of land cover (bare soil plus seven vegetation classes). Each of these is characterized by only a few parameters. One of the original features of the scheme is that it allows the simultaneous existence of these eight covers in a grid box of the climate model. Calculations of the evapotranspiration rate are performed separately for each surface type, and the total latent heat flux transferred to the atmosphere is taken to be the average of evaporation from bare soil, transpiration, and interception loss from each of the seven vegetation types. This scheme, named SECHIBA ("Schématisation des Echanges Hydriques à l'Interface entre la Biosphère et l'Atmosphère," Ducoudré 1990), has been introduced in our AGCM, and results of the water budget simulated for July are described. We also developed the zero-dimensional version of SECHIBA and present its response to a number of prescribed atmospheric variables measured in an area located in the Amazonian forest.

\section{The $\mathrm{LMD}$ atmospheric general circulation model}

The LMD Atmospheric General Circulation Model (AGCM) is defined on a grid constant in longitude and in sine of latitude. It has 64 points in longitude and 50 points in latitude. The vertical coordinate is $\sigma$, the ratio of local pressure to surface pressure, and the 11 levels are unevenly spaced in $\sigma$. The grid is a uniform area, and four layers are defined in the boundary layer, four in the troposphere, and three in the stratosphere. The model was described in Sadourny and Laval (1984) or Laval and Picon (1986), and we give only a brief description here.

- The prognostic variables are surface pressure $P_{s}$, potential enthalpy $\theta=c_{p} T / \pi$ (where $\pi=P^{\chi}$, $\chi$ $\left.=R / c_{p}\right)$, water vapor mixing ratio, and horizontal velocity components. The primitive equations are solved with a time step of 6 minutes. For lateral diffusion, a bi-Laplacian for both potential enthalpy and rotational wind is used, while a single Laplacian acts on the divergent part of the wind. The four lowermost layers correspond to the planetary boundary layer (with a top at $\sigma=0.77$ ), where turbulent diffusion is parameterized.

- There are two kinds of condensation processes: (i) when the air is supersaturated and the temperature lapse rate is less than the moist adiabatic lapse rate, water vapor is condensed and temperature rises owing to the release of latent heat, until the mixing ratio reaches the saturation value at the new temperature; (ii) when the air is conditionally unstable, with a temperature lapse rate exceeding the moist adiabatic lapse rate, small-scale convection can occur. For supersaturated air, we use the moist convective adjustment (Manabe and Strickler 1964). When the air is not saturated and conditionally unstable, condensation occurs in areas of moisture convergence. Here we follow Kuo's (1965) parameterization of cumulus convection, where the cloud top is defined as the level where the buoyancy condition vanishes.

- Each time condensation occurs cloudiness is generated, and the computations of radiative fluxes are performed with this distribution of clouds (Le Treut and Laval 1984). To calculate solar radiative heating, we use the scheme defined by Fouquart and Bonnel (1980): it takes into account absorption by water vapor, carbon dioxide, and ozone, as well as scattering by cloud drops. There is no diurnal variation. The cooling due to longwave radiation is computed with the scheme of Katayama (1972).

Whenever the amount of carbon dioxide is less than $0.3 \mathrm{~cm} \mathrm{NTP,} \mathrm{the} \mathrm{transmission} \mathrm{function} \mathrm{is} \mathrm{modified}$ according to the Sasamori (1968) approximation.

- Both ground temperature $T_{g}$ and bulk heat capacity $C$ are defined as mean quantities over a surface layer of a depth over which vertical variation of temperature at a one-day time scale is significant. The ocean temperature is prescribed.

- Surface albedo is prescribed following Bartman's (1980) data. The surface drag coefficient equals 5.24 $\times 10^{-3}$ in the summer hemisphere, and $7 \times 10^{-3}$ in the winter hemisphere.

One can argue that the surface albedo and drag coefficient must depend on the surface type, and therefore, have to be parameterized as a function of the vegetation classes we defined $(\$ 4 a)$. This is certainly true. Nevertheless, our point in the work presented in this paper was to introduce some simple equations to describe the hydrologic processes linked with vegetation, such as transpiration, interception loss, and water storage on foliage and in the soil, in a model where the parameterization of the land surface was very crude: all land points were evaporating as a bare soil. So the drag and albedo were kept as they were. Since the latter is climatologically defined, it takes roughly into account the mean vegetal cover of the grid. The simplification of a constant drag coefficient is certainly a weakness of the model. However, note that the aerodynamic resistance is generally quite lower than the surface resistance over a vegetated area.

The integrations of the AGCM presented hereafter have been carried out for two months, starting 11 June 1979. The initial state was defined from ECMWF analyzed data. 
TABLE 1. In SECHIBA, equations for (i) the gradient of specific humidity between the evaporating surface and the overlying air, (ii) the fraction of the grid box that is evaporating, and (iii) the sum of the resistances opposing the flux of water vapor. All three terms are given for the four components of the total latent heat flux: snow sublimation, soil evaporation, canopy transpiration, and interception loss. The mathematical symbols are listed and described in appendix B.

\begin{tabular}{llccc}
\hline \hline & $\begin{array}{c}\text { Snow } \\
\text { sublimation }\end{array}$ & $\begin{array}{c}\text { Soil } \\
\text { evaporation }\end{array}$ & $\begin{array}{c}\text { Canopy } \\
\text { transpiration }\end{array}$ & $\begin{array}{c}\text { Evaporation } \\
\text { of foliage water }\end{array}$ \\
\hline$\Delta q=$ & $q_{\mathrm{sat}}\left(T_{g}\right)-q_{a}$ & $h_{g} q_{\mathrm{sat}}\left(T_{g}\right)-q_{a}$ & $h_{g} q_{\mathrm{sar}}\left(T_{g}\right)-q_{a}$ & $q_{\mathrm{sat}}\left(T_{g}\right)-q_{a}$ \\
$\alpha=$ & $\frac{S_{n}}{S_{\mathrm{cr}}}$ & $\left(1-\frac{S_{n}}{S_{\mathrm{cr}}}\right)\left(1-\sigma_{f}\right)$ & $\left(1-\frac{S_{n}}{S_{\mathrm{cr}}}\right) \sigma_{f}\left(1-\left(\frac{W_{\mathrm{dew}}}{W_{d \max }}\right)^{2 / 3}\right)$ & $\left(1-\frac{S_{n}}{S_{\mathrm{cr}}}\right) \sigma_{f}\left(\frac{W_{\mathrm{dew}}}{W_{d \mathrm{max}}}\right)^{2 / 3}$ \\
$\Sigma_{1} r_{1}=$ & $r_{a}$ & $r_{a}+r_{g}$ & $r_{a}+r_{0}+r_{c}$ & $r_{a}+r_{0}$ \\
\hline
\end{tabular}

\section{Parameterization of the hydrologic exchanges between the soil/vegetation system and the atmosphere}

SECHIBA is a set of parameterizations describing 1) the exchanges of water vapor between the soil/vegetation system and the atmosphere, that is, the latent heat flux, and 2) the soil hydrologic cycle. Both are detailed below.

Vegetation is treated as a single equivalent surface absorbing radiative energy, but since several surface types are allowed to be present simultaneously within the same grid box (bare soil plus seven vegetation classes, §4a), calculation of evapotranspiration is performed for each of them. The total flux of latent heat transferred to the atmosphere is then calculated as the average of all these individual participations.

Each class of vegetation is considered a single layer canopy model. Its roots extract soil water that is transpired by the dry fraction of the foliage (i.e., the fraction that has no water stored on its surface). Evaporation of the intercepted rainfall (or of the dew) occurs at the potential rate. Since the prescribed fraction of the grid box occupied by vegetation is actually the sheltered part, we neglect direct evaporation of the soil below canopy. Only the unsheltered part evaporates.

For calculations of sensible heat flux and radiative budget, soil and vegetation are considered as one medium. A number of the land-surface models included within AGCMs have a similar assumption (Abramopoulos et al. 1988; Noilhan and Planton 1989; Warrilow et al. 1986). Only the Biosphere-Atmosphere Transfer Scheme (BATS) developed by Dickinson et al. (1986) and the Simple Biosphere model ( $\mathrm{SiB})$ described in Sellers et al. (1986) solve independent energy budgets for canopy and ground.

\section{a. Latent heat flux}

Total latent heat flux $\left(E_{a}\right)$ is computed as the weighted average of snow sublimation $\left(E_{s}\right)$, soil evaporation $\left(E_{g}\right)$, canopy transpiration $\left(E_{\mathrm{tr}}\right)$, and evaporation of foliage water ( $E_{i}$, intercepted precipitation and dew). Each of these fluxes is computed using the following expression:

$$
E_{s, g, \mathrm{tr}, i}=\alpha_{s, g, \mathrm{tr}, i} \rho \frac{\Delta q_{s, g, \mathrm{tr}, i}}{\sum_{1} r_{\mathbf{l}}} .
$$

They are driven by $\Delta q_{s, g, \mathrm{tr}, i}$, the gradient of specific humidity between the evaporating surface and the overlying air, and limited by a sum of resistances $\left(r_{1}\right)$. Here $\alpha_{s, g, t r, i}$ is the fraction of the grid box evaporating, and $\rho$ the air density. In Table 1 , the detailed formulations of $\Delta q_{s, g, t r, i}, \alpha_{s, g, t r, i}$, and $r_{1}$ are summarized. This bulk equation has been introduced by Monteith (1963) and is known, for canopy evapotranspiration, as the "big-leaf" or "single-leaf" model.

- The aerodynamic resistance $\left(r_{a}\right)$ is present in all fluxes and opposes the transfer of water vapor from the surface-air interface to the air at the reference level chosen in the atmosphere ( $10 \mathrm{~m}$ above ground in the LMD AGCM). Here, $r_{a}$ is inversely proportional to the product of the surface drag coefficient $\left(C_{d}\right)$ and of the wind speed $\left(V_{a}\right)$. We present in Table 2 the calculations of all the resistive terms.

TABLE 2. In SECHIBA, equations for the resistive terms opposing the different components of the total latent heat flux. The mathematical symbols are listed and described in appendix B.

Aerodynamic resistance

$$
r_{a}=\frac{1}{C_{d} V_{a}}
$$

Soil resistance

$$
r_{g}=r_{\text {soil }} \frac{D_{u}}{D_{t}} \frac{W_{u \max }-W_{u}}{W_{u \max }}
$$

Architectural resistance

$$
r_{0}=\text { a function of vegetation type (see Table } 3 \text { ) }
$$

Canopy resistance

$$
r_{c}=\frac{1}{\mathrm{LAI}} \frac{R_{s}+R_{s 0}}{R_{s}} \frac{a+\lambda \cdot \delta c}{k_{0}}
$$

Surface relative humidity (retention coefficient)

$$
h_{g}=\exp \left(-c \frac{D_{u}}{D_{t}} \frac{W_{u \max }-W_{u}}{W_{u \max }}\right)
$$


- Soil evaporation in SECHIBA is calculated from the bulk aerodynamic method, combining the use of the surface relative humidity $\left(h_{g}\right)$ with the definition of a soil resistance $\left(r_{g}\right)$. Both $h_{g}$ and $r_{g}$ are functions of soil moisture. Soil resistance is proportional to the relative dryness of the upper soil layer (Table 2). The coefficient of proportionality is the resistance the upper soil layer would exert on the evaporation of the water located below if it was totally dry. It is calculated as the resistance of $1 \mathrm{~m}$ of dry soil $\left(r_{\text {soil }}\right)$, derived from measurements from a variety of soil types $(\$ 4 a)$, times the ratio between the variable depth of the upper soil layer $\left(D_{u}, \S 3 \mathrm{c}\right)$ and the depth of the total soil layer $\left(D_{t}\right)$.

Dickinson et al. (1986) in BATS and Abramopoulos et al. (1988) in the land-surface model introduced in the GISS GCM used another category of formulations: the so-called threshold methods based on the concept of demand and supply. These methods compare the potential evaporation computed with the aerodynamic method $\left(h_{g}=1\right.$, and $\left.r_{\text {soil }}=0\right)$ to a maximum diffusive water flux through the soil-air interface. The problem with this approach is that it requires considerable information on the soil hydraulic properties.

Mahfouf and Noilhan (1991) compared various formulations of evaporation from bare soil. According to their sensitivity tests, the type of method we use, referred to as the " $\beta$ method," works rather well in predicting the daily evaporation rate, while the threshold methods strongly underestimate surface evaporation during the whole period of observations that they used to compare their simulations. Moreover, the latter methods seem highly sensitive to the depth of the top soil layer.

- The concept of architectural resistance $\left(r_{0}\right)$ has been introduced by Perrier (1975). It represents the aerodynamic resistance between the leaves and the canopy top. As noted by McNaughton (1987), the concept of canopy conductance as the total conductance of all leaves is not realistic because the whole canopy is not perfectly ventilated and there is a variation, within the foliage, of the gradient of specific humidity between the evaporating surface and the overlying air. Our assumption of a single layer canopy prevents us from representing this effect, and thus, we introduced a resistive term to approach it as in Saugier and Katerji (1991).

- The canopy resistance $\left(r_{c}\right)$, as calculated here, includes both bulk stomatal and leaf aerodynamic resistances. It depends on incident solar radiation $\left(R_{s}\right)$ and on the water vapor concentration deficit of the air $(\delta c)$ simulated above canopy and is inversely proportional to the single-sided leaf area index (Table 2). Our formulation is semi-empirical and has been derived by Lohammar et al. (1980) from Jarvis (1976) on the basis of extensive measurements. The parameters entering the calculation of $r_{c}$ have to be estimated from field measurements $(\$ 4 a)$. McNaughton and Jarvis
(1991) carried on calculations at the leaf, canopy, and regional scales to study the sensitivity of transpiration to a change in stomatal conductance. They showed that, due to a number of environmental negative feedbacks, this sensitivity decreases as the spatial scale increases.

The expression we use does not depend on soil moisture, in part because of the lack of reliable quantitative information on the subject. The limitation of canopy transpiration due to soil water stress is taken into account through the surface relative humidity $\left(h_{g}\right)$ entering the calculation of $\Delta q_{\mathrm{tr}}$ (Table 1). In BATS (Dickinson et al. 1986) $r_{c}$ is computed assuming no water stress. The calculated transpiration rate $\left(E_{\mathrm{tr}}\right)$ is then compared to a maximum sustainable transpiration rate $\left(T_{r \max }\right)$, a function of soil and canopy properties and of soil moisture. If necessary, $r_{c}$ is linearly increased so that $E_{\mathrm{tr}}$ never exceeds $T_{r \text { max }}$.

- Calculations of the gradients of specific humidity ( $\Delta q_{\mathrm{tr}}$ and $\Delta q_{g}$ ) between the evaporating surface and the air above involve the definition of $h_{g}$, the so-called surface relative humidity. For soil evaporation it represents the relative humidity of the air at the land surface. For canopy transpiration it simulates the retention of water molecules by the soil, making it harder for the plants to extract them. As the soil becomes drier, the retention forces increase, and $h_{g}$ decreases. This phenomenon has been described by Perrier (1975). We have parameterized the surface relative humidity as a function of soil water content (Table 2), and the same formulation is used for both fluxes.

\section{b. Foliage moisture}

When it rains and/or when there is dew formation, the leaves become covered with a film of water before drip-through carries water to the ground. This water can reevaporate at the potential rate (interception loss, $\left.E_{i}\right)$, but at the same time transpiration is suppressed over the wet leaves. We do not explicitly account for the interception of snowfall by the foliage but assume that for more than a critical amount of snowfall, set equal to $0.015 \mathrm{~m}\left(S_{\mathrm{cr}}\right)$ of equivalent liquid water depth (Blondin 1988), vegetation is not allowed to transpire. In this case the only latent heat flux that takes place is snow sublimation.

The amount of water intercepted by the foliage is controlled by incident rainfall $\left(P_{r}\right)$ and interception loss. It is limited by a maximum water storage $\left(W_{d \max }\right)$ proportional to the single-sided leaf area index (section 4a). Then following Deardorff (1978),

$$
\begin{gathered}
\frac{\partial W_{\text {dew }}}{\partial t}=\sigma_{f} P_{r}-E_{i} \\
W_{\text {dew }} \leqslant W_{d \text { max }} .
\end{gathered}
$$

It is interesting to note that in all the land-surface models developed for use within AGCMs (Abramopoulos et al. 1988; Dickinson et al. 1986; Noilhan and 
Planton 1989; Sellers et al. 1986; Warrilow et al. 1986) the intercepted water has a similar one-layer parameterization. The formulations may differ, however, in the calculation of $W_{d \max }(\S 4 \mathrm{a})$ and of the fraction of wet foliage.

We must point out that SECHIBA is the only model to authorize transpiration to take over interception loss, within the same time step, if all of the intercepted water has evaporated and if the atmosphere is still unsaturated. This effect could be important if a continuous rainfall, with a rate much lower than the rate of potential evaporation, occurs over the canopy. In this case evaporation of the wet foliage, with a low interception storage capacity, can be much smaller than the transpiration that should occur after the interception loss.

\section{c. Soil moisture}

The total depth of soil considered at all land points is the root zone. The maximum water it can hold is computed as the difference between the profiles of soil moisture at saturation and at wilting point $(\$ 4 a)$. Its functioning is very simple and is ruled by the following statement: the most reactive part of the soil is the upper one. When it rains, the soil is filled from top to bottom; when evapotranspiration is larger than precipitation, water is removed from the closest level where it is available in the soil. This, in theory, leads to the creation of as many upper layers as necessary. In practice, mainly due to computer cost, we limit ourselves to two layers, that is, only one upper reservoir. Runoff occurs when the soil is saturated. Canopy transpiration ceases when the simulated soil is completely dry (i.e., at the wilting point).

This scheme has been developed and tested for cultivated areas by Choisnel $(1977,1984)$, who used it to compute the water budget over France. Laval (1988) showed that this model, when introduced into the LMD AGCM, avoids two drawbacks of the bucket model. First, it prevents the soil from an excessive drying, and second, it succeeds in simulating rapid and large fluctuations of the evaporation rate after rainfall events.

\section{d. Justification of SECHIBA: Comparing SECHIBA and the BUCKET formulation, a micrometeorological study over Manaus, Brazil}

We have developed the so-called "zero-dimensional (hereafter OD)" version of SECHIBA (hereafter SOD), that is, the land-surface scheme decoupled from the AGCM. It is driven by a number of prescribed atmospheric variables that can be obtained from in situ measurements or from AGCM simulations: 1) surface incident solar radiation, 2) infrared radiation emitted by the atmosphere and received by the soil-vegetation system, 3-4) air temperature and specific humidity above soil/vegetation, 5) surface wind speed, and 6) incident rainfall.

In the simulations we are presenting, the hourly measurements made by Shuttleworth et al. (1984a,b), $25 \mathrm{~km}$ from Manaus, Brazil, in the undisturbed tropical rainforest of the Reserva Ducke were used. Their field campaign continued for two years, starting in September 1983. This experiment is referred to in the literature as the ARME (Amazon Region Micrometeorological Experiment), and these data have already been used by Sellers et al. ( 1989 ) to validate SiB and by Dickinson et al. (unpublished work) to validate BATS.

The soil in this area is completely shaded by the canopy $\left(\sigma_{f}=1\right)$. The depth of the root zone $\left(D_{t}\right)$ and its maximum water content $\left(W_{t \max }\right)$ were derived from Sellers et al. (1989). They are, respectively, $1.5 \mathrm{~m}$ and $323.19 \mathrm{~mm}$. The foliage storage capacity equals 0.8 $\mathrm{mm}$. No tuning has been made on the parameters used to calculate the canopy resistances (LAI, $k_{0}, a, \lambda, R_{s 0}$, $\left.r_{0}\right)$ in SECHIBA: they are strictly the ones given $(\S 4 \mathrm{a})$ for a rainforest type of vegetation (Table 3 ).

From SOD we derived another land surface OD model, replacing the parameterizations of the hydrologic cycle by the bucket formulations (hereafter BOD) summarized briefly in appendix A.

- Monthly totals of the simulated evapotranspiration rates are displayed in Fig. 1 together with the values calculated by Shuttleworth (1988, hereafter S88) and with the incident precipitation rate measured in situ.

The monthly fluxes of simulated latent heat are very similar to the ones $\mathbf{S 8 8}$ calculates, even though no parameter was tuned in SECHIBA, as stated previously.

The rainfall curve shows a very marked dry season from June to November: the average monthly rate for this period is $127 \mathrm{~mm}$, less than half the average for the wet season $(301 \mathrm{~mm})$. Despite this very marked seasonal cycle, evapotranspiration does not vary that much throughout the year and is even larger during the dry season in both SECHIBA and S88: $124 \mathrm{~mm}$ in SOD (123 in S88) versus 112 from December to May

TABLE 3. In SECHIBA, canopy parameters that are prescribed.

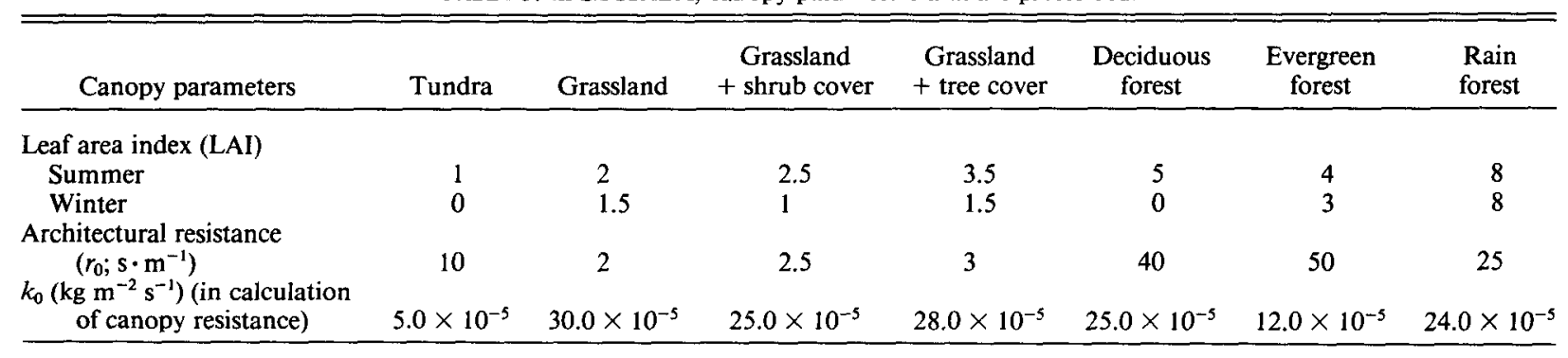




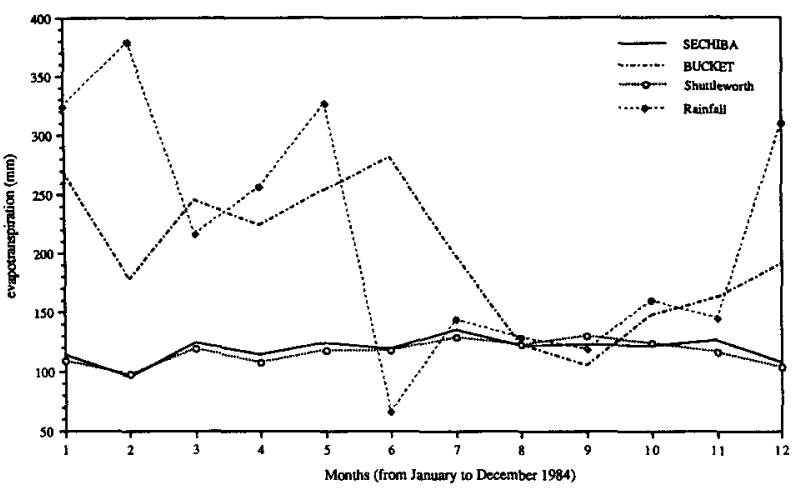

FIG. 1. Monthly rates of total evapotranspiration ( $\mathrm{mm}$ ) simulated in SECHIBA and in the bucket model, together with the rates calculated by Shuttleworth (1988) and with the monthly precipitation rate measured in situ during the ARME experiment (Shuttleworth et al. $1984 a, b)$.

(respectively 109). This imbalance between high precipitation rate and high evapotranspiration rate is due to the energy available at the surface (net radiation), which is larger during the dry season because of the larger amount of solar radiation reaching the ground. It is obvious that the bucket model is incapable of representing this feature: it follows very closely the seasonal cycle of precipitation. Evapotranspiration is lower in SOD than in BOD, mainly because of the canopy resistances opposing foliage transpiration (stomatal + architectural) and evaporation of the intercepted water (architectural). This latter flux is the maximum sustainable one in SOD, which is lower than potential evaporation in BOD in the same atmospheric conditions. During the wet season precipitation amply provides water to the soil (Fig. 2) so that evaporation takes place at the potential rate in B0D. On the contrary, from June to November the soil dries out very quickly in BOD and the aridity coefficient decreases strongly, thereby limiting the amount of water vapor that the soil is exchanging with the atmosphere.

- Hourly fluctuations (for the first 3 days in January) of the surface temperatures $\left(T_{g}\right)$ simulated in SOD and

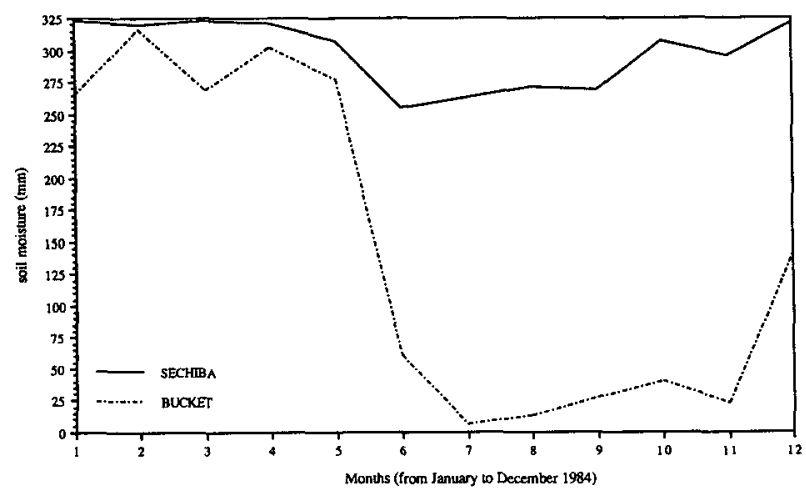

FIG. 2. Total soil water content $(\mathrm{mm})$ simulated at the end of each month in SECHIBA and in the bucket model.

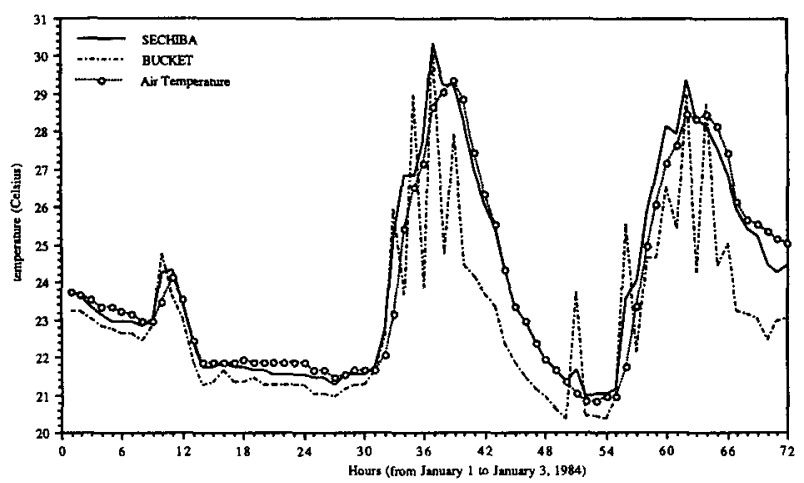

FIG. 3. Hourly values of the surface soil temperature (celsius) simulated in SECHIBA and in the bucket model, together with the temperature of the air above canopy measured in situ during the ARME experiment (Shuttleworth et al. 1984a,b). The first three days of January 1984 are displayed.

in BOD are displayed in Fig. 3, together with the air temperature measured above canopy $\left(T_{a}\right)$. Here, $T_{g}$ in SOD follows $T_{a}$ very closely, while in B0D there are important fluctuations of $T_{g}$ during daytime $(\sim$ from 0600 to 1900 local time). They are due to the formulation of evapotranspiration in the bucket model. Incident solar radiation $\left(R_{s}\right)$ increases steadily every hour from 0600 to 1100 (Fig. 4). In both models, it induces an increase in the simulated surface temperature. This in turn leads to an increase in the saturated value of specific humidity $\left[q_{\mathrm{sat}}\left(T_{g}\right)\right.$; Table 1$]$ and thereby of evapotranspiration. The latter increase counters the effect of solar radiation on $T_{g}$ : it takes energy out of the ground and leads to the decrease of $T_{g}$ obtained in B0D, since $E_{a}$ is much larger than $R_{s}$.

The conclusion of this experiment is that SECHIBA is, without any doubt, representing correctly the water vapor exchanges at the surface-atmosphere interface, while the bucket model is overestimating them in all seasons. Most of the discrepancies obtained between

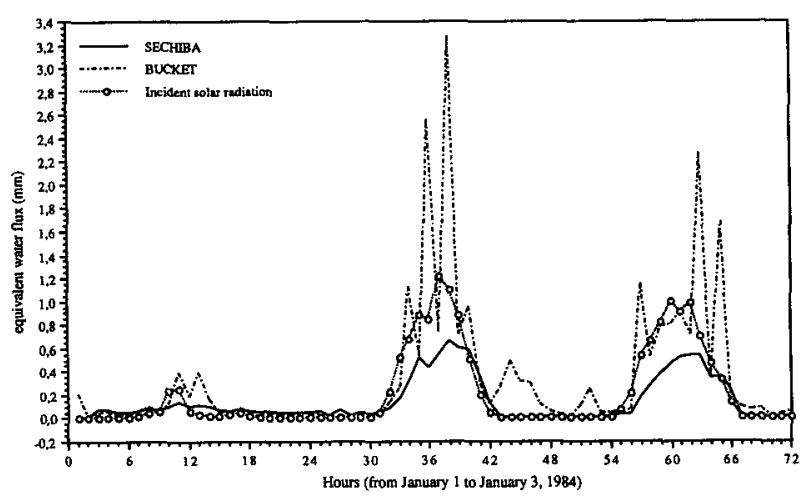

FIG. 4. Hourly rates of total evapotranspiration ( $\mathrm{mm}$ ) simulated in SECHIBA and in the bucket model, together with the incident solar radiation measured in situ during the ARME experiment (Shuttleworth et al. 1984a,b). The first three days of January 1984 are displayed. 
the models is due to the difference in the parameterization of evapotranspiration. The simulated fluxes and surface temperatures would probably become more sensitive to the changes in the formulation of soil hydrology in a less vegetated area.

\section{Implementing SECHIBA in the AGCM}

\section{a. Vegetation and soil types}

We have used the vegetation and cultivation data of Matthews (1983a,b; 1984), which is designed for incorporation into climate models. Thirty-one classes of natural land type are defined, and the intensity of cultivation is prescribed for each $1^{\circ} \times 1^{\circ}$ grid element.

To simplify the LMD AGCM land cover specification, the data archive was reduced to percentages of eight more basic land-cover classes: 1) desert, 2) tundra, 3 ) grassland, 4) grassland with shrub cover, 5) grassland with tree cover, 6) deciduous forest, 7) evergreen forest, and 8 ) rainforest. All of these can simultaneously share the same grid box. A fractional area of coverage of the grid box, as well as some prescribed canopy characteristics, are associated with each of these eight vegetation types.

- We define seven parameters for each vegetation type:

$\checkmark$ the single-sided leaf area index (LAI).

A value of LAI is assigned to each land-cover class (Table 3 ). Since we have carried out only the June to August numerical simulations of the climate, we prescribe the summer and winter values (Perrier, personal communication). If a seasonal-cycle integration was to be considered, a time-varying LAI would have to be assessed, as it is done in BATS (Dickinson et al. 1986) for example. The mean value of LAI over each grid box, computed as an average weighted by the fraction of the grid box occupied by each vegetation type, is displayed in Fig. 5a. It can be compared to the global distribution of vegetation published by UNESCO (1973; Fig. 5b);

o the maximum amount of water the canopy can hold $\left(W_{d \text { max }}\right)$.

$$
W_{d \max }=0.5 \mathrm{LAI} \text {. }
$$

The amount of water stored per LAI $(0.5 \mathrm{~mm})$ could seem rather large when compared to other land surface models, but one of our objectives was to avoid tuning the parameters, and this value had been measured over cereal fields by Huber (1987), during stormy events in 1986 in France. Warrilow et al. (1986) have derived the following linear relationship between the vegetation area index (VAI $=2 \mathrm{LAI}+$ stem area index ) and the measured maximum canopy interception:

$$
W_{d \max }=0.2 \mathrm{VAI} \text {. }
$$

The values of $W_{d \max }$ they obtain are generally lower than the ones we compute.

Rutter (1975) has assembled values of measured quantities of intercepted water. They vary from 0.4 to $2.8 \mathrm{~mm}$ depending on the vegetation type, leading to maximum capacities per LAI going from 0.16 for grasslands to $0.4 \mathrm{~mm}$ for trees.

In an AGCM that simulates rainfall as uniformly distributed within a grid box of about $10^{5}$ $\mathrm{km}^{2}$, this value can be too large. Indeed, Sellers et al. (1989) showed that a maximum storage capacity of $0.1 \mathrm{~mm}$ fits much better the observed value of interception loss than their previous capacity of $0.25 \mathrm{~mm}$;

$\diamond$ the architectural resistance $\left(r_{0}\right)$. The values were prescribed by Perrier (personal communication);

o the stomatal aperture controls transpiration and is parameterized by means of the canopy resistance $\left(r_{c}\right)$, which depends on two variables (incident solar radiation and atmospheric water vapor concentration deficit) and five parameters (Table 2):

$\diamond \diamond$ leaf area index;

$\diamond \diamond \boldsymbol{R}_{s o}$, the half light saturation factor. It is set equal to $125 \mathrm{~W} \mathrm{~m}^{-2}$ according to some measurements conducted over a 120 year old oak stand in Fontainebleau forest (near Paris, France) by Halldin et al. (1985);

$\diamond \diamond a$ and $k_{0}$, two $\delta c$ influence factors, where $a$ is set equal to $23 \times 10^{-3} \mathrm{~kg} \mathrm{~m}^{-2}$ according to the same previous authors who also provide $k_{0}$ for a deciduous forest. For the other vegetation types, values of $k_{0}$ were assigned by Perrier (personal communication);

$\diamond \Delta \lambda$ is set equal to 1.5 .

We have chosen the same values of $a, R_{s 0}$, and $\lambda$ for all vegetation types because of insufficient measured quantities.

In Figs. 6a-c the evolutions of canopy resistance are plotted as a function of incident solar radiation for a deciduous forest. Six curves are displayed on each graph corresponding to different hydric states of the atmosphere: from the lower (lowest values of $r_{c}$ ) to the upper curve, the atmospheric relative humidity varies from $100 \%$ (saturation) to $0 \%$. The water vapor concentration deficit of the air above canopy is calculated as a function of 1 ) atmospheric relative humidity, 2) surface pressure ( $1015 \mathrm{hPa})$, and 3 ) ambient temperature that changes from $30^{\circ} \mathrm{C}$ in Fig. $6 \mathrm{a}$ to $20^{\circ} \mathrm{C}$ in $6 \mathrm{~b}$ and $10^{\circ} \mathrm{C}$ in Fig. 6c.

- At all land points, bare soil is described by means of four parameters:

$\diamond$ its total depth $\left(D_{t}=1 \mathrm{~m}\right)$. It represents the root zone in our model. We assigned one single value in the model, but it will certainly be more realistic to make it a function of the vegetation type, as it 


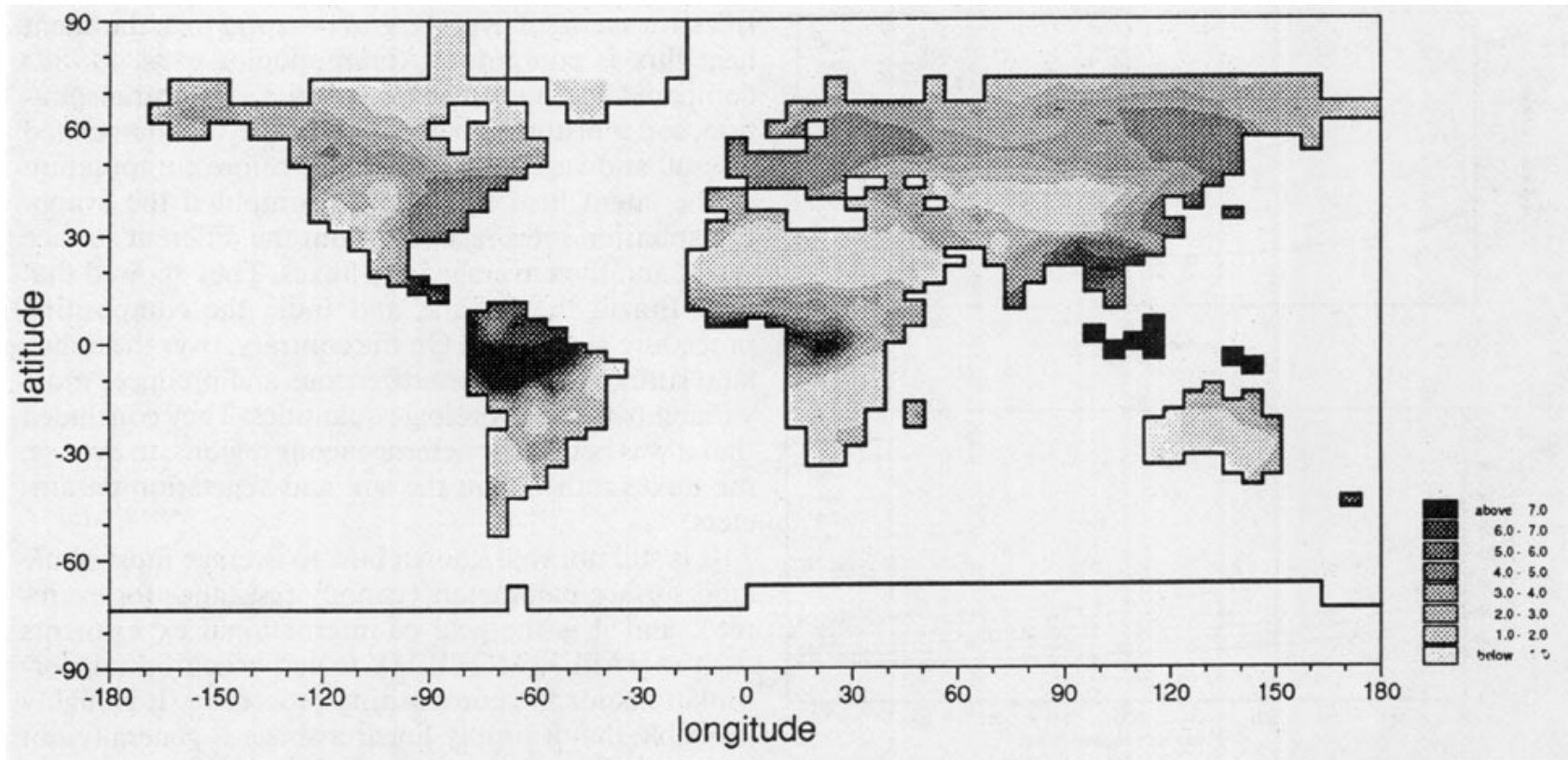

FIG. 5a. Single-sided leaf area index prescribed for use in CLAS. For each grid box a weighted average is calculated over all the vegetation types, the weight being the fraction of the grid box occupied by the type considered.

is done in BATS (Dickinson et al. 1986) and in SiB (Sêllers et al. 1986);

- the maximum amount of water it can hold $\left(W_{t_{\text {max }}}\right)$. In case of a fully covered soil, $W_{t \max }$ corresponds to the maximum amount of water that vegetation can extract from the soil. According to agronomists, it can be estimated as the difference between the profiles of soil moisture at saturation and at wilting point. Classical values of $W_{t \text { max }}$, expressed in $\mathrm{kg} \mathrm{m}^{-2}$ (i.e., in millimeters of equivalent liquid water depth), are 70-80 for sand, 150 for clay, and 200 for loam. We have chosen the mean value of $150 \mathrm{~mm}$;

$\checkmark$ the resistance exerted by $1 \mathrm{~m}$ of dry soil to the evaporation of the water located below $\left(r_{\text {soil }}\right.$ $\left.=33000 \mathrm{~s} \mathrm{~m}^{-1}\right)$. It is calculated as the ratio be-

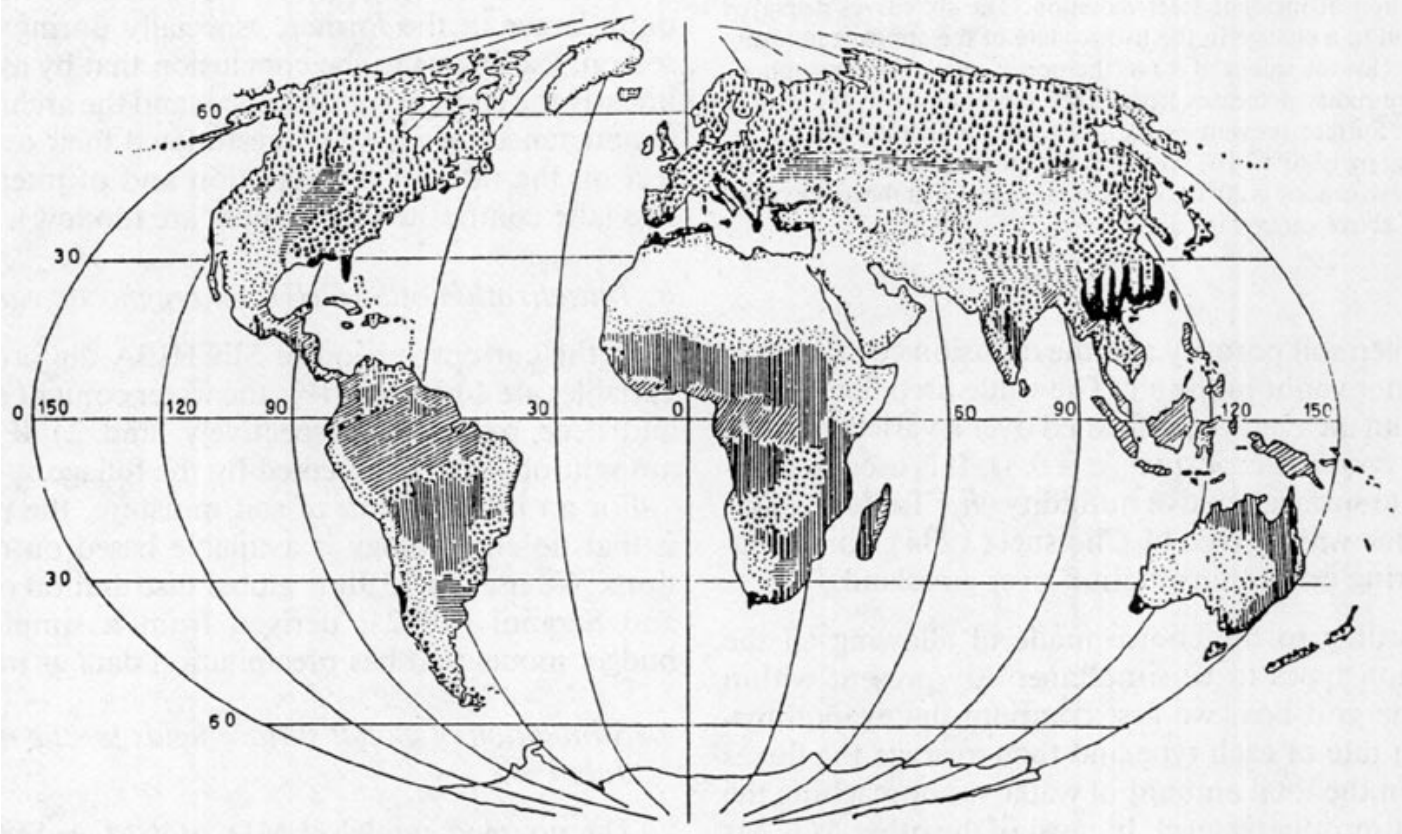

FIG. 5b. Global distribution of vegetation published by UNESCO (1973). 

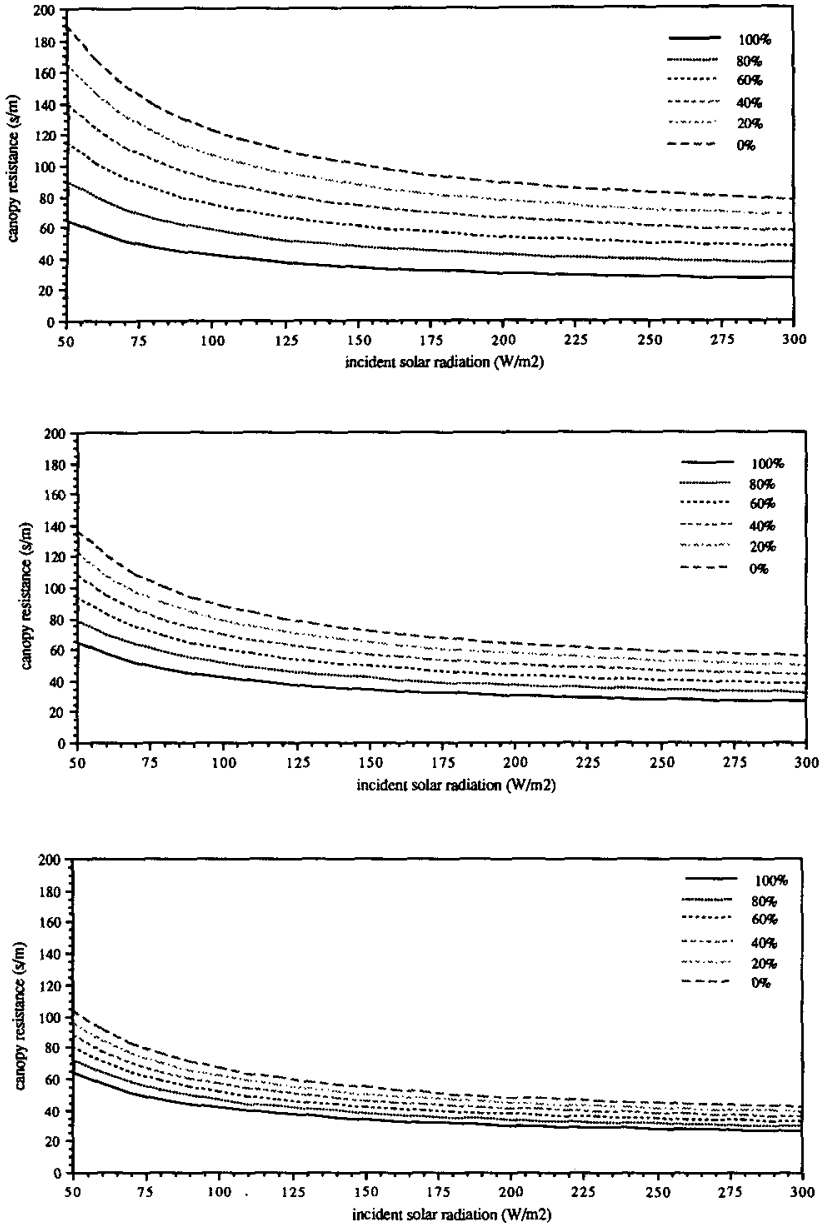

FIG. 6. (a) Canopy resistances $\left(\mathrm{s} \mathrm{m}^{-1}\right)$ calculated for a deciduous forest from the formulations used in CLAS (Tables 2 and 3), plotted as a function of incident solar radiation. The six curves displayed correspond to a change in the hydric state of the atmosphere: from the lower (lowest values of $r_{c}$ ) to the upper curve, the atmospheric relative humidity decreases from $100 \%$ (saturation) to $0 \%$, with a $20 \%$ step. Surface pressure is $1015 \mathrm{hPa}$ and temperature of the air above canopy is $30^{\circ} \mathrm{C}$. (b) As in (a) except that the temperature of the air above canopy is $20^{\circ} \mathrm{C}$. (c) As in (a) except that the temperature of the air above canopy is $10^{\circ} \mathrm{C}$.

tween soil porosity and the diffusion coefficient of water vapor in the air. The value used here comes from an average performed over a variety of soils;

$\checkmark$ an empirical constant $(c=0.8)$. It is used to compute surface relative humidity $\left(h_{g}\right.$; Table 2$)$. This value was derived by Choisnel (1984) while measuring evapotranspiration over grassland.

According to the choice made of allowing all the vegetation types to be simultaneously present within the same grid box, we first compute the evapotranspiration rate of each type and then average the fluxes to obtain the total amount of water vapor reaching the lowest atmospheric level. In most of the other AGCMs that include a land-surface model, canopy character- istics are averaged over the grid box, and then the latent heat flux is computed. Abramopoulos et al. (1988) compared the hydrologic quantities (evapotranspiration, soil moisture) obtained when they 1 ) composited the soil and vegetation properties before computation of the latent heat flux and 2) computed the evapotranspiration rates resulting from the different surface types, and then averaged the fluxes. They showed that over Brazil, the Sahara, and India the compositing procedure works well. On the contrary, over the Sahel, land surface is more heterogeneous and produces more variability in the hydrologic quantities. They concluded that it was better, for heterogeneous regions, to average the fluxes rather than the soil and vegetation parameters.

It is still not well known how to average most of the land surface parameters (canopy resistance for example), and it is the goal of international experiments such as HAPEX-MOBILHY to derive appropriate formulations for the compositing procedure. It is highly probable that a simply linear average is generally not representative of the mean flux, as shown by Andre and Blondin (1986) and Mason (1988) for the surface roughness length.

In order to validate our choice, an experiment was conducted with SOD using the ARME meteorological data. We assumed that the ground cover was composed of $50 \%$ rainforest and $50 \%$ grassland. Two integrations were made: 1) in SOD1 we averaged the simulated heat fluxes, and 2) in SOD2 first averaged the canopy conductances $\left(1 / r_{c}\right.$ and $\left.1 / r_{0}\right)$, the leaf area indexes, and then calculated the heat fluxes exchanged between the composited canopy and the overlying air. Figure 7 is a display of the difference between the evapotranspiration rates simulated in SOD2 and in S0D1. They are quite larger in the former, especially during the wet season, leading us to the conclusion that by averaging linearly the canopy conductances and the architectural conductances, we have overestimated their overall effect on the rates of transpiration and of interception loss (the composited resistances are too low).

\section{b. Initialization of SECHIBA's prognostic variables}

In the current version of SECHIBA the prognostic variables are 1) $W_{u}$ and $W_{d}$, the water content of upper and deep reservoirs, respectively, and 2) $W_{\text {dew }}$, the amount of water intercepted by the foliage.

For an initialization of soil moisture, the problem is that no climatology is available based on observations. We use the 15 June global distribution of Mintz and Serafini (1992), derived from a simple water budget model that has precipitation data as inputs.

\section{c. Simulation of global surface fields for the month of July}

The coupled model (LMD AGCM + SECHIBA, hereafter CLAS) ran for two months starting 11 June. 


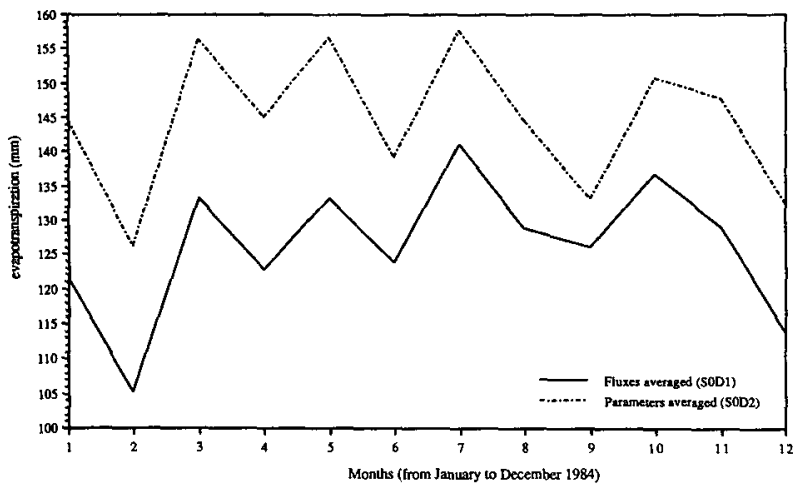

FIG. 7. Monthly rates of total evapotranspiration ( $\mathrm{mm}$ ) simulated in SOD1 and in SOD2. In SOD1 the fluxes of latent heat are first calculated for each vegetation type and then averaged; in S0D2 the canopy resistances are first averaged and then the flux of latent heat is calculated,

Here the water budget over the globe is shown in terms of the July average.

- The evapotranspiration rate simulated in CLAS is displayed in Fig. $8 \mathrm{a}$. The highest values $\left(>4 \mathrm{~mm}\right.$ day $\left.^{-1}\right)$ are found (i) in areas where the foliage's density is important, that is, over the semper virens and deciduous forests of Europe and Siberia, on the east coast of the United States where deciduous forests are dominant, and over the tropical rainforests of Amazonia and Africa and (ii) in areas where rainfall is abundant (intertropical convergence zone).

This distribution may be compared to the one obtained by Sato et al. (1989) when they coupled the Simple Biosphere model to the NMC AGCM (Fig. 8b). Both models simulate a maximum larger than $5 \mathrm{~mm}$ day $^{-1}\left(\sim 150 \mathrm{~W} \mathrm{~m}^{-2}\right)$ over the northern part of South America and over the regions influenced by the Asian monsoon. Over the United States they generate very similar extensions of areas with an averaged evapotranspiration rate of $3.5 \mathrm{~mm}^{\text {day }}{ }^{-1}$, as well as of the deserts (in California and Arizona) recognizable by their very low latent heat flux $\left(<1 \mathrm{~mm} \mathrm{day}^{-1}\right)$.

There is no climatology of evapotranspiration based on global measurements of this quantity. We can, however, compare our simulation with the calculation performed by Mintz and Serafini (1992; hereafter MS92; Fig. 8c) using the simple water budget model mentioned earlier ( $\$ 4 b)$. Regions of low evapotranspiration rate $\left(<1 \mathrm{~mm}\right.$ day $\left.^{-1}\right)$, which may be classed as arid or semiarid, are less extended in CLAS than in MS92 over the Sahara, the southwest part of Africa (Kalahari Desert), and Australia. Maxima of latent heat flux are generally more important in CLAS-for example, over the Amazonian forest or the eastern part of the United States. However, this comparison must be made with caution because the MS92 distribution, however, is not based on observations, it is just another model using observed temperature and precipitation as input.
- Canopy evapotranspiration is split into interception loss and transpiration ( $\$ 3 \mathrm{a})$, which are displayed in Figs. 9a and 9b. Wherever precipitation rates are larger than $2 \mathrm{~mm} \mathrm{day}^{-1}$ (Fig. 10a) the simulated interception loss is greater than $1 \mathrm{~mm}$ day $^{-1}$, as in the middle and high northern latitudes and in the ITCZ. Maxima ( $>2 \mathrm{~mm}$ day $^{-1}$ ) are found in the tropical rainforests of America and Asia, over Alaska, over the northwest part of the Rocky Mountains, the east coast of the. United States, Labrador, the Scandinavian countries, and over the eastern part of Siberia. In most of these regions transpiration is lower than interception loss.

According to the measurements made by Shuttleworth (1988) near Manaus ( $\$ 3 d$ ), contribution of interception loss to the total latent heat flux calculated in July is approximately $20 \%$. In CLAS interception loss and transpiration participate equally with canopy evapotranspiration in this area. We believe that the large canopy water storage capacity prescribed $\left(W_{d \max }\right.$; $\S 4 a)$ is responsible for this imbalance between "observed" and simulated values. Despite this discrepancy, the simulated total latent heat flux is comparable to the estimate of Shuttleworth (1988).

In the tundra-covered regions of north Canada, the grassland countries of Iran, Kazakhstan, southern Asia, and southern California, interception loss is the dominant process of evapotranspiration. The soil in these areas is quite dry, thereby strongly limiting transpiration by means of the surface relative humidity $\left(h_{g}\right.$; Table 1).

- The precipitation rates simulated in CLAS are displayed in Fig. 10a. The maxima are larger than $6 \mathrm{~mm}$ day $^{-1}$ and are located in the ITCZ. Intensive rainfall is also obtained over the Tibetan Plateau and can be compared to the maximum simulated by Sato et al. (1989; Fig. 10b). In Alaska, the Rocky Mountains, Labrador, the Appalachian Mountains, Patagonia, the Scandinavian Mountains, in the mountains of central and eastern Siberia, and in the Drakensberg, precipitation is greater than $4 \mathrm{~mm}^{-1 a y}{ }^{-1}$ and exceeds the observations made by Jaëger (1983; Fig. 10c). They are quite comparable though to the values calculated by Sato et al. (1989). More generally, comparisons made with other AGCMs showed that these models tend to overestimate rainfall over elevated regions.

The low precipitation rates $\left(<1 \mathrm{~mm} \mathrm{day}{ }^{-1}\right)$ simulated in Africa (Sahara, northern Sahel, Kalahari), Arabia, West Asia (Gobi), California (Mojave), and South America are quite comparable to the observations.

- The global distribution of total soil water content is displayed Fig. 11a and compared to the initial one (Fig. 11b). Most of the land surfaces have experienced a drying of their soil: arid and semiarid regions ( $W_{t}$ $<15 / 30 \mathrm{~kg} \mathrm{~m}^{-2}$ ) grew larger in the southern parts of Europe, of the former USSR and of the United States, in Africa southward of $30^{\circ} \mathrm{S}$, and in South America 

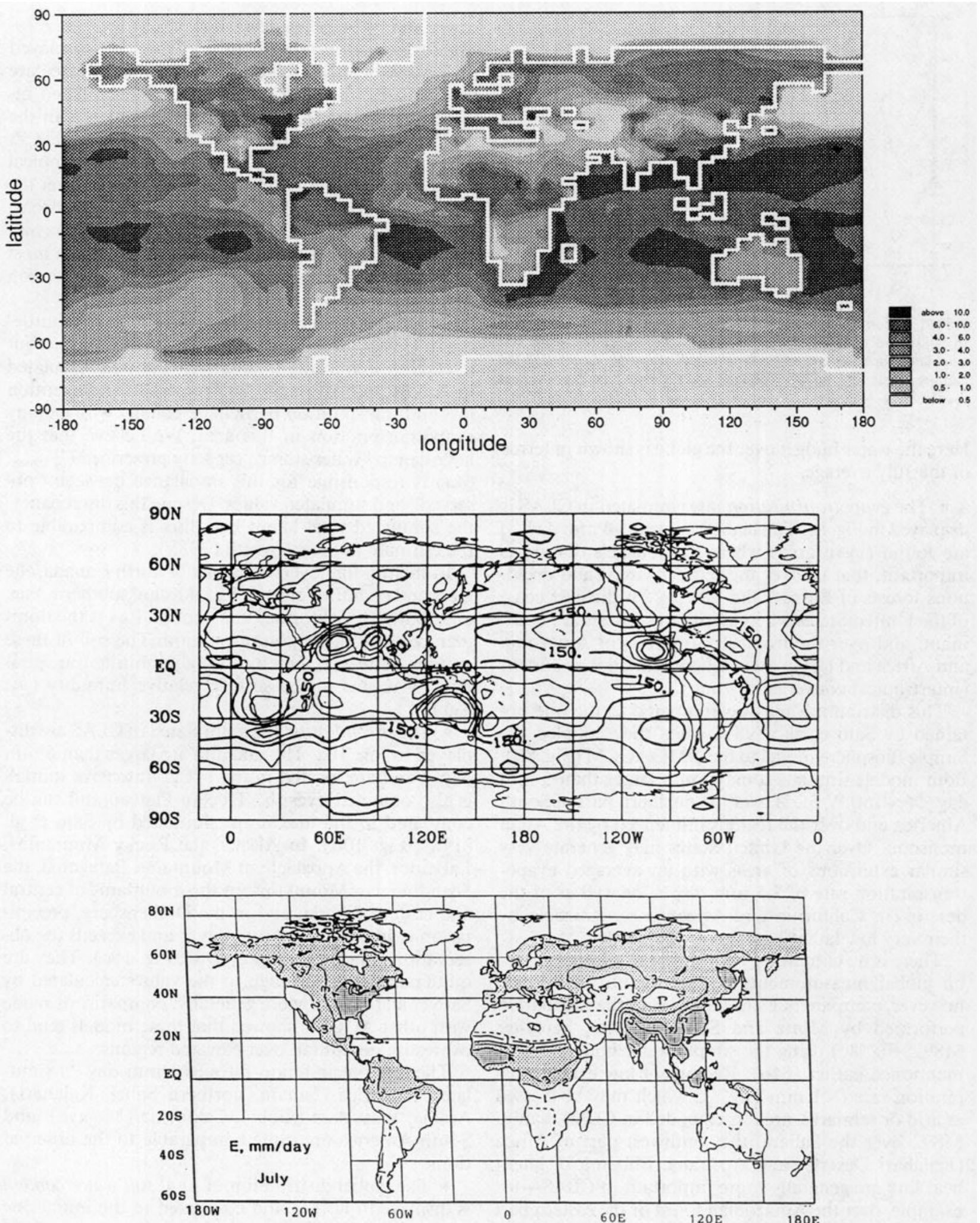

FIG. 8. (a) Total evapotranspiration rate $\left(\mathrm{mm} \mathrm{day}^{-1}\right)$ simulated in CLAS and averaged over July. (b) Total evapotranspiration rate ( $\mathrm{W} \mathrm{m}^{-2}$ day $^{-1}$ ) simulated in the coupled model NMC AGCM-SiB (Sato et al. 1989) and averaged over 30 days starting 15 June. The contour interval is $50 \mathrm{~W} \mathrm{~m}^{-2}$ day $^{-1}$; land regions where the simulated mean latent heat flux exceeds $150 \mathrm{~W} \mathrm{~m}^{-2}$. day ${ }^{-1}$ have been shaded. (c) Total evapotranspiration rate $\left(\mathrm{mm} \mathrm{day}^{-1}\right)$ calculated by Mintz and Serafini (1992) for July. The contour interval is $1 \mathrm{~mm}$ day ${ }^{-1}$; dashed line is $0.5 \mathrm{~mm}$ day $^{-1}$ 

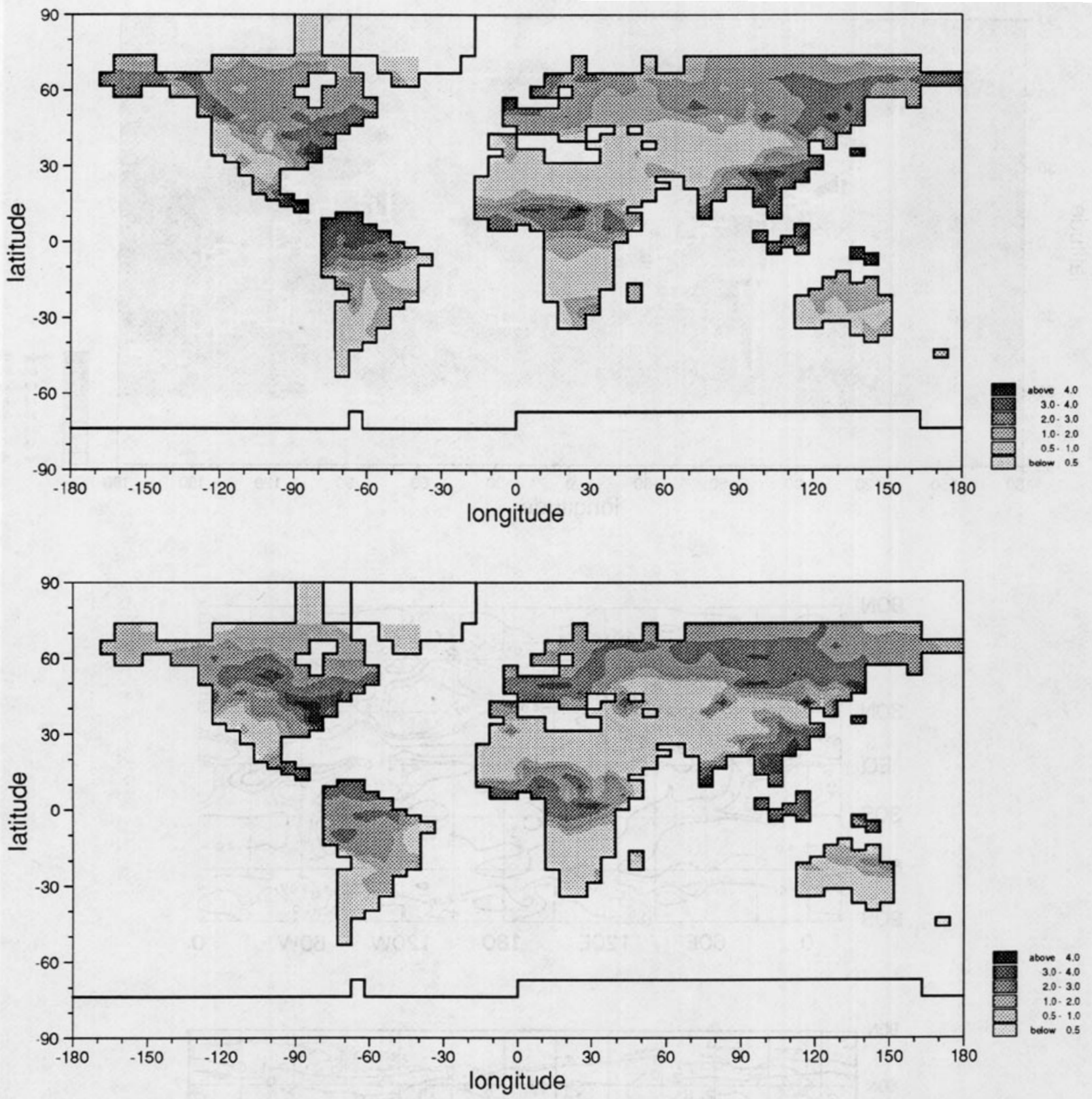

FIG. 9. Rate of (a) interception loss and (b) canopy transpiration ( $\mathrm{mm} \mathrm{day}^{-1}$ ) simulated in CLAS and averaged over July.

around $10^{\circ} \mathrm{S}$. Most of these patterns sound realistic since, at that time of the year and at those latitudes, evapotranspiration generally exceeds precipitation.

In the southeast United States the simulated rainfall is very low and is held responsible for the low values of soil moisture we obtained.

Even though there is no existing climatology of soil moisture, it is interesting to compare the variations of soil moisture simulated here to the ones calculated by MS92 between 15 July and 15 June (Fig. 11c). Their overall distributions of drying and moistening do not differ markedly from ours. The exceptions are South- east Asia, which dries out in CLAS and not in MS92, and the northern part of North America, which becomes more humid. We remind the reader at this point that soil moisture is distributed in two layers in CLAS and its functioning is very different from MS92, who consider only one soil layei.

\section{d. Regional moisture and energy budget simulated in Amazonia}

Here we consider the July moisture and energy budgets, calculated as the average of all grid boxes within 

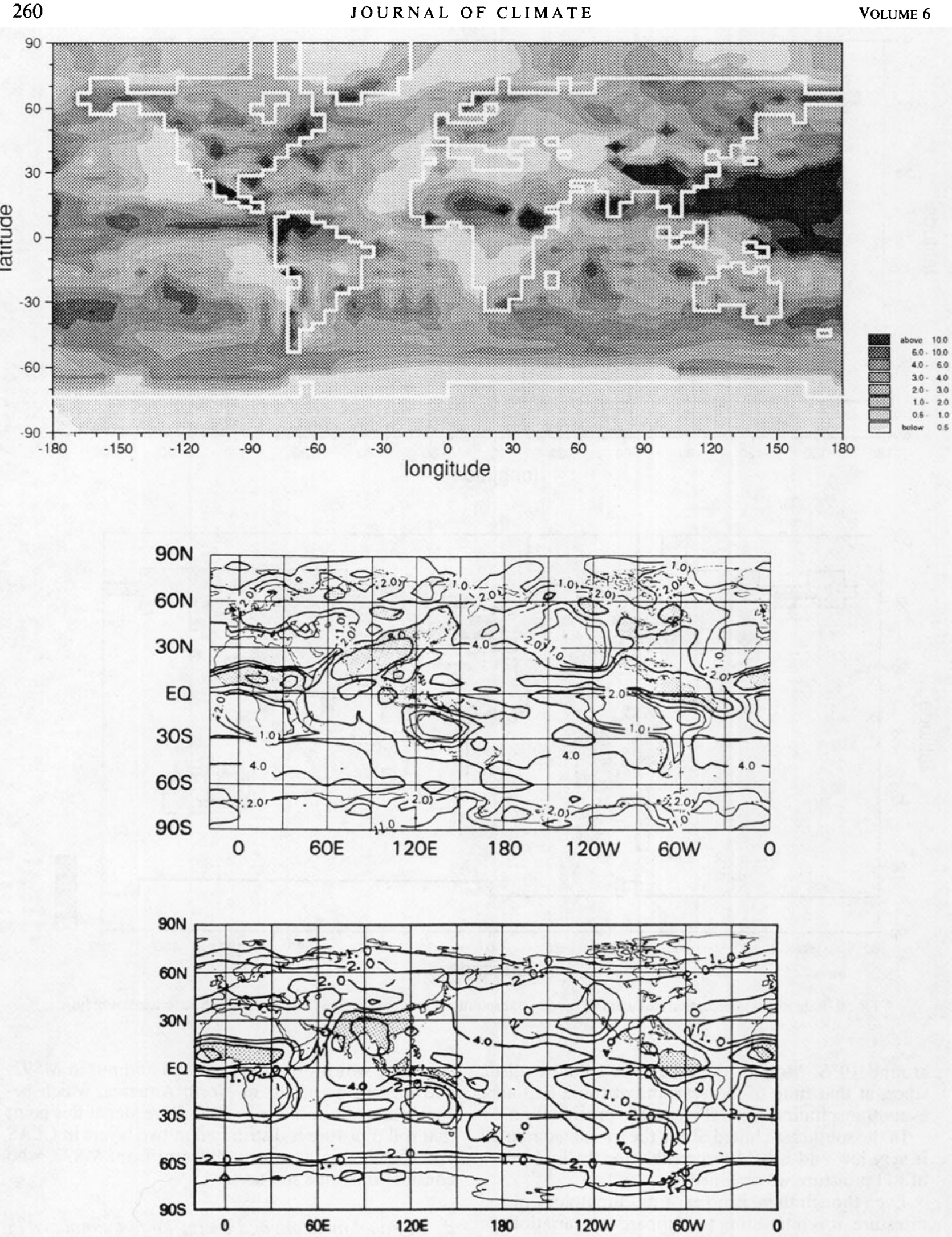

FIG. 10. Rate of incident precipitation ( $\mathrm{mm} \mathrm{day}^{-1}$ ) simulated (a) in CLAS and averaged over July and (b) in the coupled model NMC AGCM-SiB (Sato et al. 1989) and averaged over 30 days starting 15 June. The contour intervals are 1, 2, 4, and $8 \mathrm{~mm}^{-1 a y}{ }^{-1}$; land regions where rainfall rate exceeds $4 \mathrm{~mm} \mathrm{day}^{-1}$ have been shaded. (c) As in (b) but as observed by Jaëger (1983). 

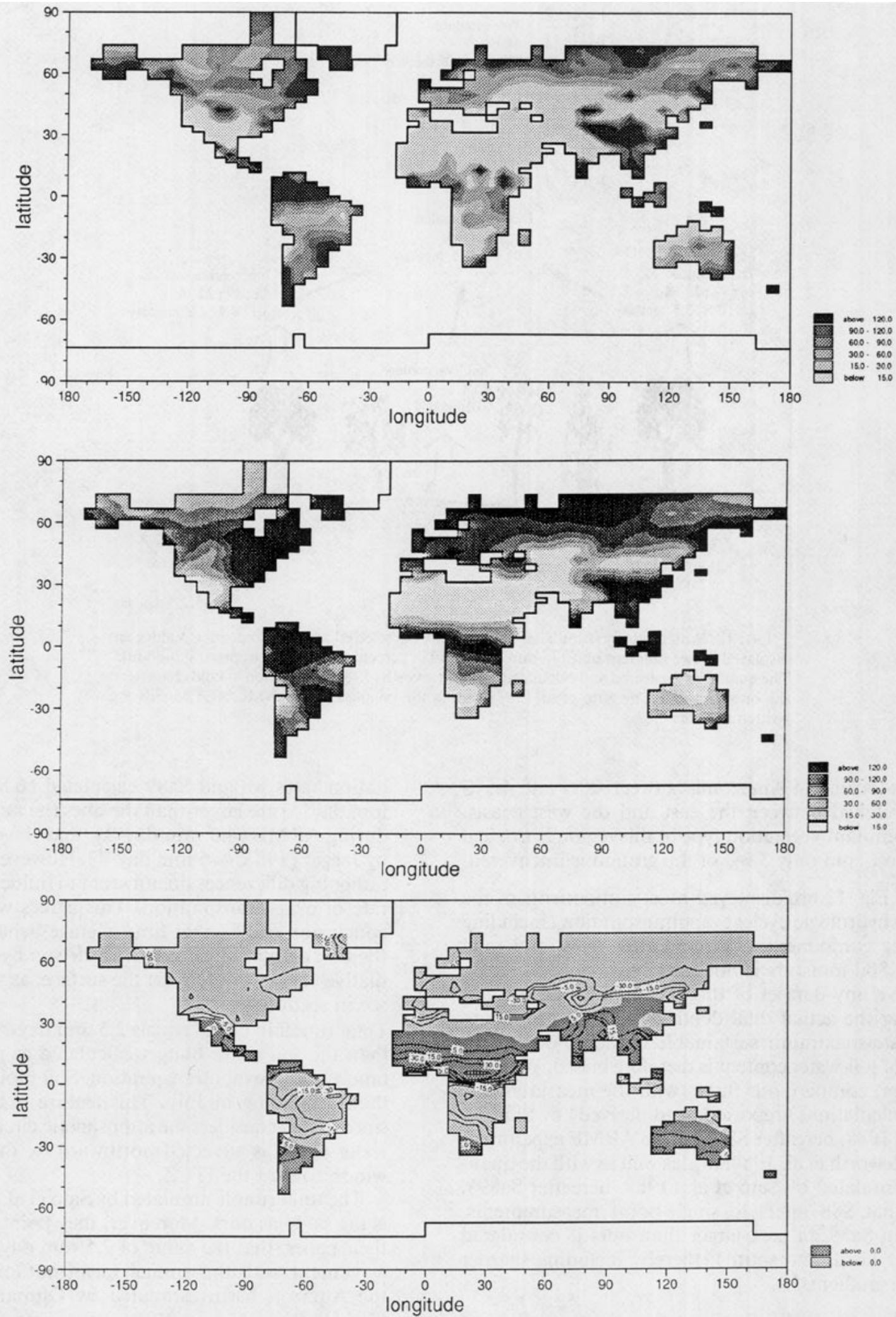

FIG. 11. (a) Total soil water content ( $\mathrm{mm}$ ) simulated in CLAS and averaged over July. (b) Initial distribution of total soil water content in CLAS. It was derived by Mintz and Serafini (1992) for 15 June. (c) Difference in total soil water content between 15 July and 15 June, as calculated by Mintz and Serafini (1992). Regions that have experienced a drying of their soil between 15 June and 15 July are lightly shaded; contour intervals are $\pm 30, \pm 15$, and $\pm 5 \mathrm{~mm}$. 


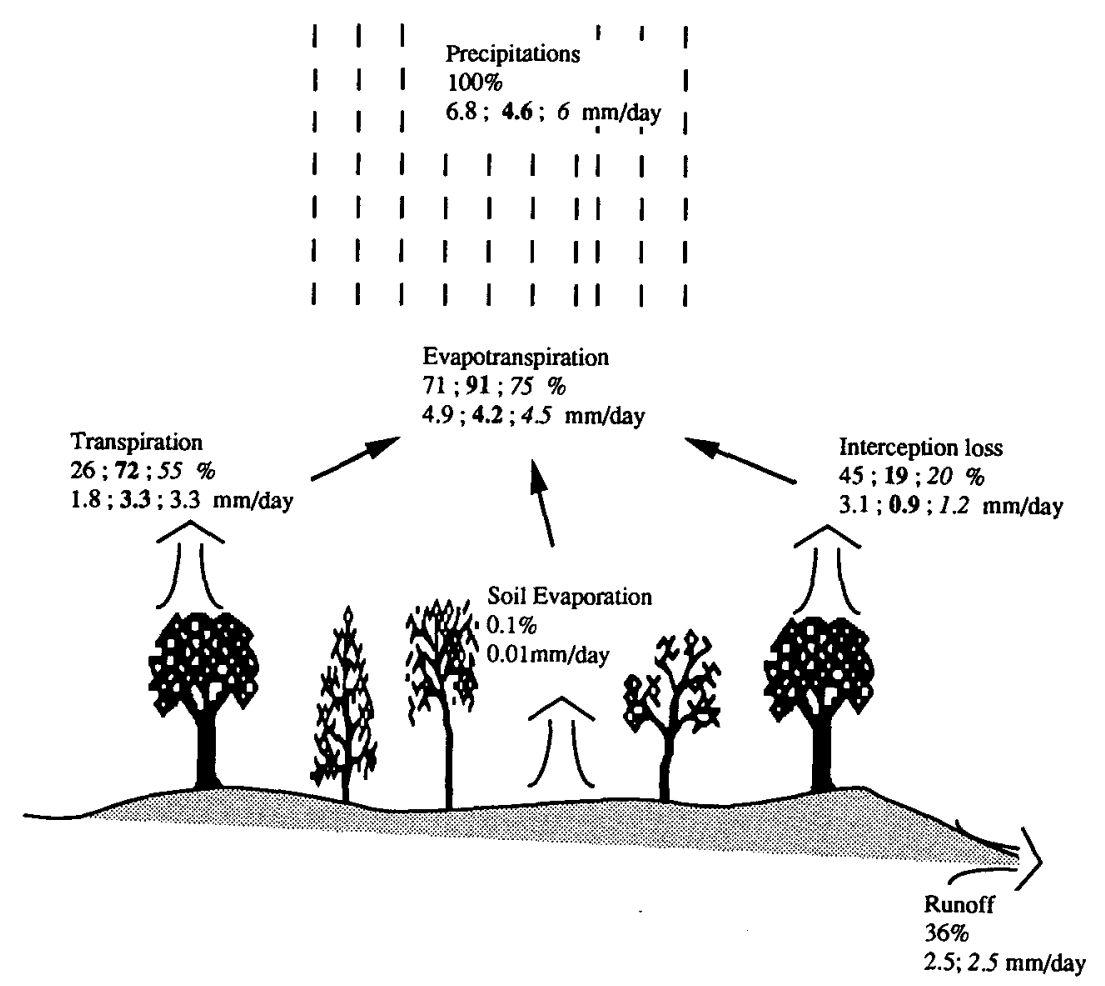

FIG. 12. Water balance simulated in CLAS for the selected area in Amazonia. Values are displayed in two different units: in $\mathrm{mm} \mathrm{day}^{-1}$ and in percent of the incident precipitation rate. The quantities measured and calculated by Shuttleworth (1988) are written in bold characters; the ones simulated by Sato et al. (1989) using the coupled model NMC AGCM-SiB are written in italic.

an area located in Amazonia between $2^{\circ} \mathrm{N}$ and $4.5^{\circ} \mathrm{S}$ and stretched between the east and the west coasts. The dominant vegetation type in this region is tropical rainforest, and only $5.3 \%$ of the ground is uncovered.

- In Fig. 12 are displayed most components of the surface hydrologic cycle: evapotranspiration (including its three components), precipitation rates, and total runoff. Soil moisture is not considered since 1 ) we do not have any dataset of this area and 2) we did not consider the actual total depth of soil nor use its appropriate maximum sustainable capacity; our calculation of soil-water content is therefore biased. We may, however, compare our fluxes with the measurements (and calculations) reported (and derived) by Shuttleworth (1988, hereafter S88) for the ARME experiment (Shuttleworth et al. 1984a,b), as well as with the quantities simulated by Sato et al. (1989, hereafter Sa89). Note that S88 refers to single-point measurements, while in Sa89 an area larger than ours is considered (farther north and south), thereby including sharper rainfall gradients.

$\diamond$ The averaged latent heat flux that we obtained $\left(4.9 \mathrm{~mm} \mathrm{day}^{-1}\right)$ is quite similar to the ones derived by $\mathrm{S} 88\left(4.2 \mathrm{~mm} \mathrm{day}^{-1}\right)$ and simulated by $\mathrm{Sa} 89$ $\left(4.5 \mathrm{~mm} \mathrm{day}^{-1}\right)$. On the other hand, the precip- itation rates we and $\mathrm{Sa} 89$ calculated ( 6.8 and 6 $\mathrm{mm} \mathrm{day}^{-1}$ ) are larger than the ones (a) measured during ARME (4.6 mm day ${ }^{-1}$ ), and (b) derived by Jaëger ( $1983 ; 4-5 \mathrm{~mm}$ day $\left.^{-1}\right)$. However, these rather big differences do not seem to influence the rate of evapotranspiration. This agrees with the conclusion of S88 that time-average behavior of the flux of latent heat is mainly driven by the radiative energy available at the surface, as we may see in section $4 \mathrm{e}$.

$\diamond$ Total runoff in CLAS equals $2.5 \mathrm{~mm}^{\text {day }}{ }^{-1}$, larger than the soil water budget calculated as precipitation minus evapotranspiration. Soil moisture is then decreasing in July. This feature is realistic since, if one considers the atmospheric circulation, water vapor is advected northward by the trade winds, toward the ITCZ.

The total runoff simulated by Sato et al. (1989) is the same as ours. Moreover, they point out, in their paper, that the value of $2.5 \mathrm{~mm} \mathrm{day}^{-1}$ is in agreement with the annual mean outflow from the Amazon basin estimated by Oltman et al. (1964).

$\checkmark$ The differences in the participation of interception loss to total evapotranspiration between CLAS and SiB, CLAS and S88, are quite important: the 
TABLE 4a. In SECHIBA and BATS, equations for (i) canopy transpiration, (ii) interception loss, and (iii) soil evaporation. The mathematical symbols are listed and described in appendix $B$.

\begin{tabular}{lll}
\hline \hline Transpiration & SECHIBA & BATS \\
$E_{\mathrm{tr}}=\rho \sigma_{f}\left(1-\left(\frac{W_{\text {dew }}}{W_{d \max }}\right)^{2 / 3}\right) *$ & $\frac{h_{g} q_{\mathrm{sat}}\left(T_{g}\right)-q_{a}}{r_{a}+r_{0}+r_{c}}$ & $\frac{q_{\mathrm{sat}}\left(T_{c}\right)-q_{a}}{r_{a}+r_{\mathrm{la}}+r_{c}}$ \\
Interception loss & $E_{\mathrm{tr}} \leqslant T_{r \max }$ \\
$E_{i}=\rho \sigma_{f}\left(\frac{W_{\text {dew }}}{W_{d \max }}\right)^{2 / 3} *$ & $\frac{q_{\mathrm{sat}}\left(T_{g}\right)-q_{a}}{r_{a}+r_{0}}$ & $\frac{q_{\mathrm{sat}}\left(T_{c}\right)-q_{a}}{r_{a}+r_{\mathrm{la}}}$ \\
Soil evaporation & $\left(1-\sigma_{f}\right) \frac{h_{g} q_{\mathrm{sat}}\left(T_{g}\right)-q_{a}}{r_{a}+r_{g}}$ & $\left(1-\sigma_{f}\right) \frac{q_{\mathrm{sat}}\left(T_{g}\right)-q_{a}}{r_{a g}+r_{a}}+\sigma_{f} \frac{q_{\mathrm{sat}}\left(T_{g}\right)-q_{a}}{r_{a c}}$ \\
$E_{g}=\rho *$ & $E_{g} \leqslant E_{g \max }$
\end{tabular}

amount of water stored within foliage and then evaporated is overestimated in CLAS. Again, we stress the point that the canopy storage capacity prescribed here is too large. The major difference between our simulation and $\mathrm{S} 88$, on one hand, and $\mathrm{Sa} 89$, on the other, is the partition of total latent heat flux into transpiration and interception loss. This, however, does not affect the total amount of water vapor that the surface transmits to the overlying atmosphere.

- The latent heat flux simulated in CLAS accounts for $88 \%$ of the surface net radiation, and the sensible heat flux for $12 \%$. Over the whole period of ARME (two years starting September 1983) 89.5\% of the net radiant energy measured above canopy was used to evaporate the soil-vegetation water. Shuttleworth (1988) observed that, on clear days, typically $75.8 \%$ of the energy available was converted into evapotranspiration, while on rainy days, evaporating water from the wet canopy routinely absorbs energy in excess of that locally available in its radiative form. $\mathrm{S} 88$ derived a value of $93.5 \%$ for July.

We have compared the regional moisture budgets simulated in Amazonia by SECHIBA and SiB (Sato et al. 1989). The parameterizations of the hydrologic exchanges at the land-atmosphere interface are very different in both models, $\mathrm{SiB}$ being more complex and requiring prescription of many more canopy and soil parameters. Despite these very large discrepancies, the flux of latent heat and the rate of runoff they simulate in July are very similar.

\section{e. Comparing SECHIBA and BATS: $A$ micrometeorological study over Manaus, Brazil}

We now compare, using the single-point measurements of ARME, the latent heat fluxes and soil water contents simulated in SOD to the ones calculated using

TABLE 4b. In SECHIBA and BATS, equations for the time evolution of the water contents of (i) the total soil layer, (ii) the root zone, and (iii) the upper soil layer. The mathematical symbols are listed and described in appendix $B$.

\begin{tabular}{lll} 
SECHIBA & BATS \\
\hline
\end{tabular}

Total soil moisture

$$
\frac{\partial W_{t}}{\partial t}=\left(1-\sigma_{f}\right) P_{r}+R_{c}-E_{g}-E_{t r} \quad R_{t} \quad R_{s u}-R_{b}
$$

Soil moisture in root zone

$$
\frac{\partial W_{r}}{\partial t}=\quad \frac{\partial W_{t}}{\partial t} \quad\left(1-\sigma_{f}\right) P_{r}+R_{c}-E_{g}-E_{\mathrm{tr}}-R_{s u}+\gamma_{r t}-G_{r t}
$$

Soil moisture in upper layer

$$
\frac{\partial W_{u}}{\partial t}=
$$

$W_{u}$ is calculated by the method developed by Choisnel $(1977,1984)$ $\left(1-\sigma_{f}\right) P_{r}+R_{c}-E_{g}-f \cdot E_{\mathrm{tr}}-R_{s u}+\gamma_{u r}-G_{u r}$ Ot 


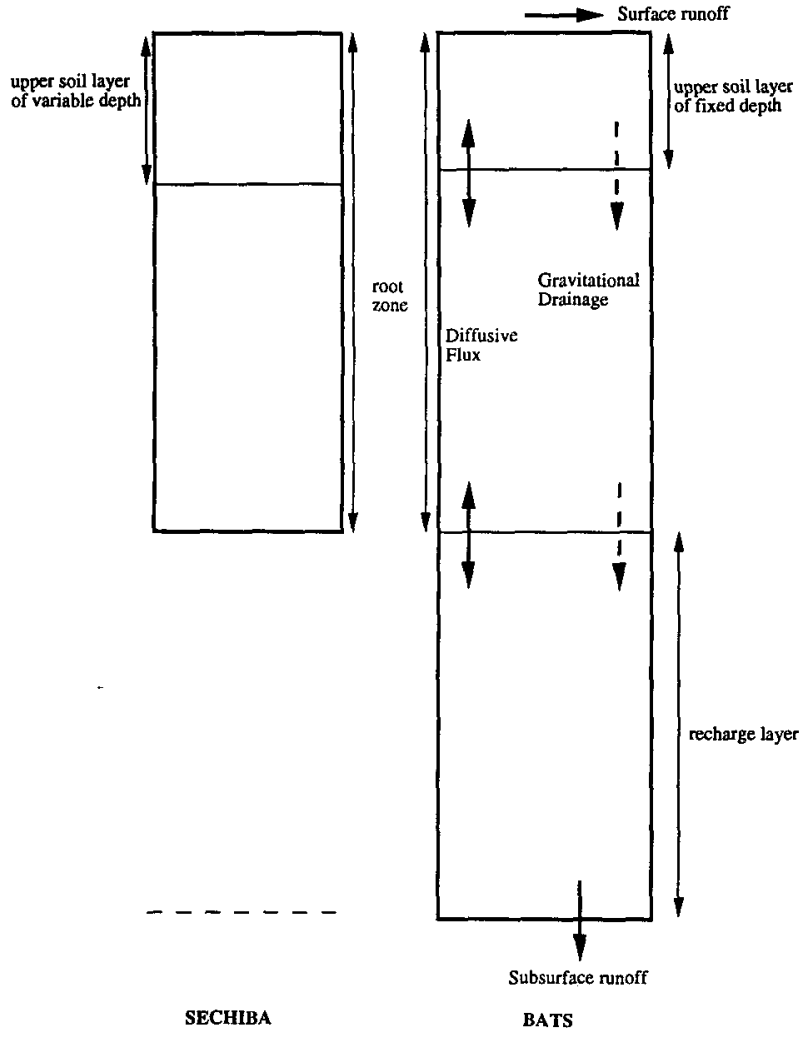

FIG. 13. Schematic representation of the soil in SECHIBA and in BATS.

the first version of BATS (Dickinson et al. 1989, unpublished work). Differences between both models mainly regard the surface hydrologic cycle (Ducoudré and Dickinson 1991) and are summarized in Tables $4 \mathrm{a}, \mathrm{b}$ and Fig. 13 and as follows.

- SECHIBA considers only one surface temperature, while BATS differentiates between foliage and soil temperatures.

- Soil moisture stress limits canopy transpiration by means of the surface relative humidity in SECHIBA, by means of a maximum sustainable transpiration rate in BATS, a function of canopy and soil characteristics and of soil moisture.

- Calculation of canopy resistance in SECHIBA implicitly includes the foliage aerodynamic resistance, while BATS gives an explicit formulation of it. On the other hand, BATS does not consider the architectural resistance.

- Transpiration is allowed to take over interception loss within the same time step in SECHIBA, but not in BATS.

- Soil moisture stress limits soil evaporation by means of a combination of soil resistance and surface relative humidity in SECHIBA, by means of a maximum sustainable diffusive flux through the soil-air interface in BATS.
- The total depth of soil considered in SECHIBA is the root zone, while BATS also takes into account the so-called recharge layer. In a previous version of BATS (Dickinson et al. 1986), the latter layer was not present. It has been included in order to avoid a complete drying of the soil for long integrations of the NCAR CCM (Dickinson, personal communication).

- No water exchange is allowed between the upper and the lower soil layers in SECHIBA, while BATS calculates upward/downward diffusive fluxes and gravitational drainage at both soil interfaces.

- Total runoff in SECHIBA is calculated as the excess water over saturation, while two components are considered in BATS: 1) surface runoff, a function of rainfall intensity and water content of the upper soil layer, and 2) subsurface runoff, a function of a prescribed maximum subsoil drainage and of the wetness of the total soil.

Both models were integrated for one year starting on 1 January 1984 (as in $\$ 3 d$ ). The evapotranspiration rates $\left(E_{a}\right)$ simulated in SECHIBA and in BATS are displayed in Fig. 14a, together with the rates calculated by Shuttleworth (1988). They are very similar in SOD and in S88 and quite larger than in BATS over the whole year. The differences obtained are essentially due to canopy transpiration $\left(E_{\mathrm{tr}}\right)$ since 1$)$ the rates of interception loss are very similar in all three "models" and 2) soil evaporation does not participate at all in total latent heat flux in SOD ( $100 \%$ of covered ground) and is quite small in BATS $\left(\sim 8 \%\right.$ of $\left.E_{a}\right)$. There are two reasons for $E_{\mathrm{tr}}$ to be larger in BATS:

(i) the canopy resistances simulated in the latter are always larger than in SOD (yearly average of $\sim 150$ versus $45 \mathrm{~s} \mathrm{~m}^{-1}$ ); they are even larger than the sum of canopy and architectural resistances calculated in SECHIBA;

(ii) the limiting effect of a drier soil on the maximum sustainable transpiration rate $\left(T_{r \max }\right)$ calculated in BATS lowers more drastically the offer $\left(E_{\mathrm{tr}}\right)$ than does the surface relative humidity in SECHIBA.

We have verified these two points by carrying on two other simulations with BATS. In Bats 1 the canopy resistances $\left(r_{c}\right.$ and $\left.r_{\mathrm{la}}\right)$ are replaced by the ones calculated in SOD $\left(r_{c}\right.$ and $\left.r_{0}\right)$. In Bats 2 we have neglected the limiting effect of $T_{r \max }$, in addition to the changes in Bats 1. The canopy transpiration rates simulated in all four models are displayed in Fig. 14b. During the wet season (from December to May) the differences obtained between SOD and Bats 1 are very small. They are larger during the dry season $\left(\sim 3.3 \mathrm{~mm}\right.$ month $\left.^{-1}\right)$ because of $T_{r \text { max }}$. The reason for $E_{\mathrm{tr}}$ to become larger in Bats2 than in S0D from June to November is the surface relative humidity that still limits the water vapor flux in SECHIBA.

Changes in total soil moisture content are quite similar in both models (Fig. 14c). By the end of the year, 


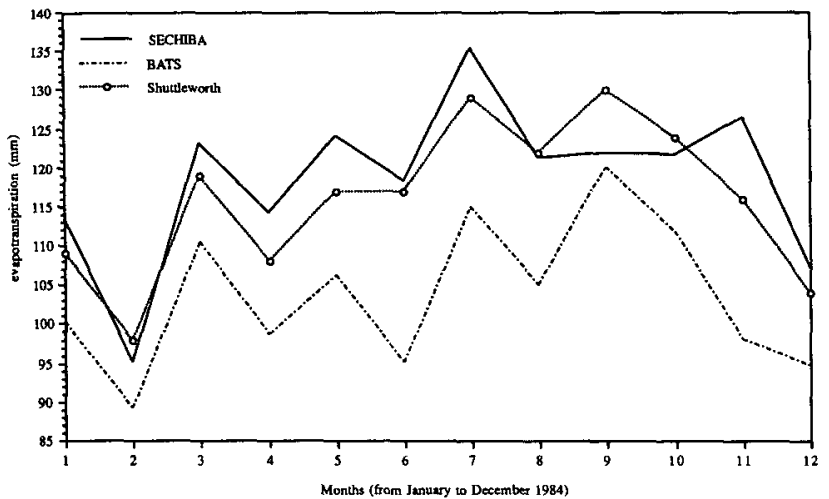

FIG. 14a. Monthly rates of total evapotranspiration ( $\mathrm{mm}$ ) simulated in SECHIBA and in BATS, together with the rates calculated by Shuttleworth (1988).

110 and $86 \mathrm{~mm}$ of water have been added to the initial soil water content respectively in SECHIBA and BATS. This occurs even though the losses by evapotranspiration are quite lower in the latter simulation (a difference of $178 \mathrm{~mm}$ summed over the whole year) and are due to the surface and subsurface runoffs in BATS. In S0D, during the entire dry season, soil water supply is not important enough to induce a runoff that remains null, while in BATS total runoff equals $306 \mathrm{~mm}$.

The latent heat fluxes and soil-water contents simulated in SECHIBA are now discussed as well as BATS for 1) the two wettest (rainiest) days of 1984, 26-27 February, and 2) the two driest, 6-7 June. The precipitation rates measured for both $48 \mathrm{~h}$ are displayed in Fig. $15 \mathrm{a}$, and the calculated evapotranspiration rates in Figs. 15b,c. The diurnal evolutions of these fluxes are quite similar in both models but are larger in SECHIBA during the intense rainfall events of daylight hours (especially in February). This difference follows from the choice of allowing canopy transpiration to take over interception loss within the same time step. In the same figures the results are plotted of a simulation carried out with SECHIBA in which we forbade it (Sech 1 ). It is obvious that SOD and Sech 1 differ only when precipitation is large, which thereby strengthens our choice since our monthly cumulated values are closer to Shuttleworth's calculations than is BATS.

In Figs. 16a-d are displayed for February and June the water contents of the upper soil layer $\left(W_{u}\right)$ and of the root zone $\left(W_{r}\right)$ simulated in SECHIBA and BATS. In February the total depth of soil considered in SECHIBA is very close to saturation. It follows that the upper soil layer does not exist but that the upper 10 $\mathrm{cm}$ of soil are very close to $21.5 \mathrm{~mm}$. Differences of $W_{r}$ between the models are quite large and result from the very large gravitational drainage simulated in BATS, which drains water downwards toward the recharge layer. During the driest episodes of June the evolutions of upper soil moisture are quite similar in

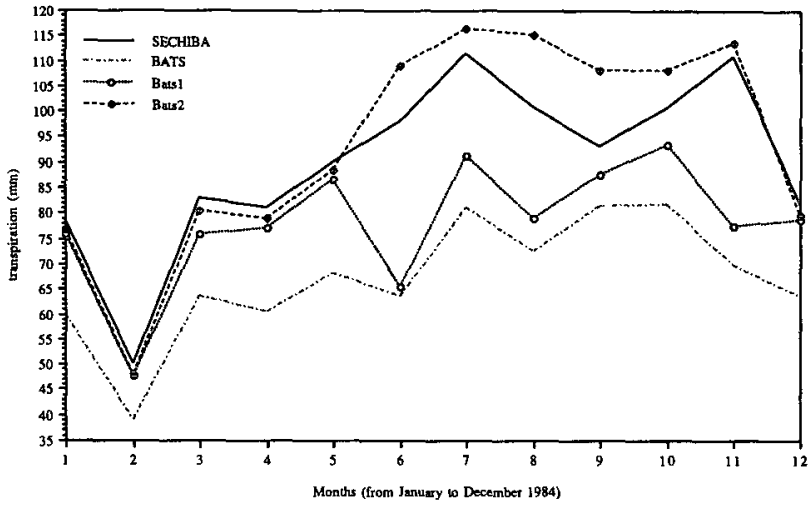

FIG. 14b. Monthly rates of total evapotranspiration (mm) simulated in SECHIBA, in BATS, in Bats1, and in Bats2. In Bats1 the canopy resistances calculated in BATS are replaced by the ones calculated in SECHIBA; in Bats 2 the limiting effect of the maximum sustainable transpiration rate is neglected, in addition to the changes in Bats1.

both models, even though the parameterizations are very different. For the root zone, the behaviors are comparable but the contents are different, again due to the important gravitational drainage at the lower soil interface in BATS.

Parameterizations of the latent heat flux and of the soil hydrologic cycle are very different in SECHIBA and BATS. They are more sophisticated in the latter, and this model, therefore, requires the prescription of more soil and canopy characteristics. As an example, only four parameters are needed in SECHIBA to describe the soil versus ten in BATS. Moreover, some of the vegetation characteristics in SECHIBA have been derived for only one type (deciduous forest) and assumed to be the same for all the others since we were lacking in situ measurements. Despite all these discrepancies and assumptions, our simulations are closer to the calculations made by Shuttleworth (1988), when compared to BATS.

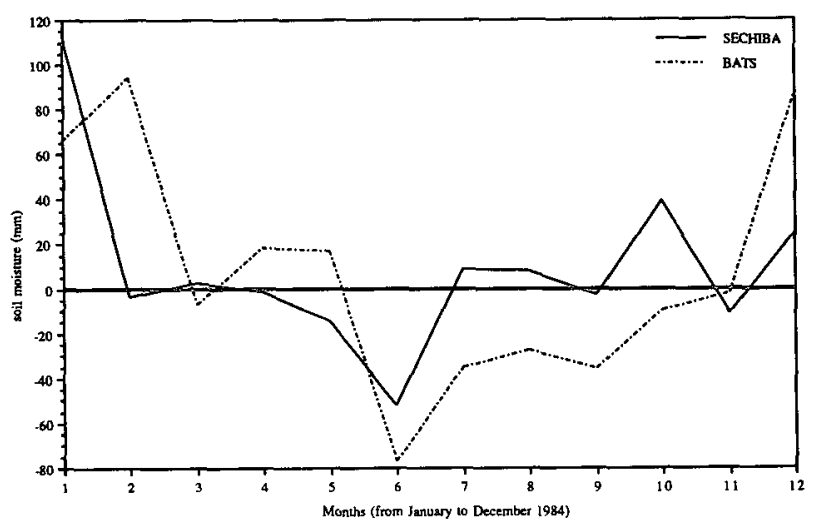

FIG. 14c. Monthly changes in the total soil water content ( $\mathrm{mm}$ ) simulated in SECHIBA and in BATS. Differences are between the end and the beginning of each month. 


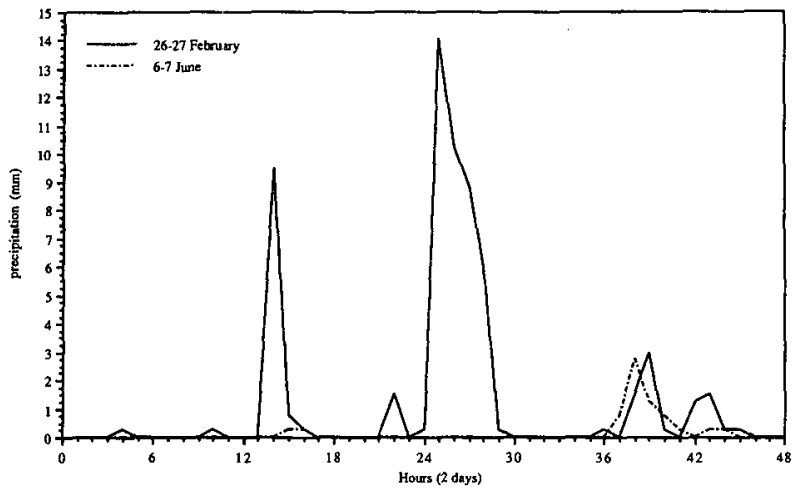

FIG. 15a. Hourly precipitation rates $(\mathrm{mm})$ measured in situ during the ARME experiment (Shuttleworth et al. 1984a,b). Two 48-h periods are displayed: 26 to 27 February and 6 to 7 June 1984 .

Comparisons between both models showed that calculations of canopy/soil resistances and of the limiting effect of soil moisture stress on both canopy transpiration and soil evaporation are what really influences the fluxes of latent and sensible heat.

\section{A review of some sensitivity experiments carried on with SECHIBA coupled to the AGCM}

We have carried on three sensitivity experiments with the coupled model (CLAS):

- In CLAS1 vegetation is replaced at all land points by bare ground. This global overgrazing might seem rather crude but it will help us understand the kind of errors one could face assuming the land surface to be homogeneously bare;

- in CLAS2 the initial soil water content (Fig. 17) is changed. The soil is much drier than in the Mintz and Serafini (1992) distribution;

- in CLAS3 vegetation at all land points is prevented from intercepting rainfall and dew. Total latent heat flux then equals the sum of canopy transpiration, soil evaporation, and snow sublimation.

\section{a. Global overgrazing}

In the model, when vegetation is replaced by bare ground, the surface resistance opposing the transfer of latent heat is modified. Soil resistance depends linearly on the relative moisture of the upper layer and can reach much higher values than the canopy resistances. As a consequence, the simulated latent heat flux, averaged over July, is quite smaller in CLAS1 than in CLAS (Figs. 18a and 8a). The largest differences exceed $1 \mathrm{~mm}$ day $^{-1}$ and are obtained over most of the vegetated areas, that is, in the medium and high northern latitudes $\left(40^{\circ}\right.$ to $\left.70^{\circ} \mathrm{N}\right)$ and in the intertropical convergence zone. One can see a large shrinking of the maxima located in the northeast part of the United

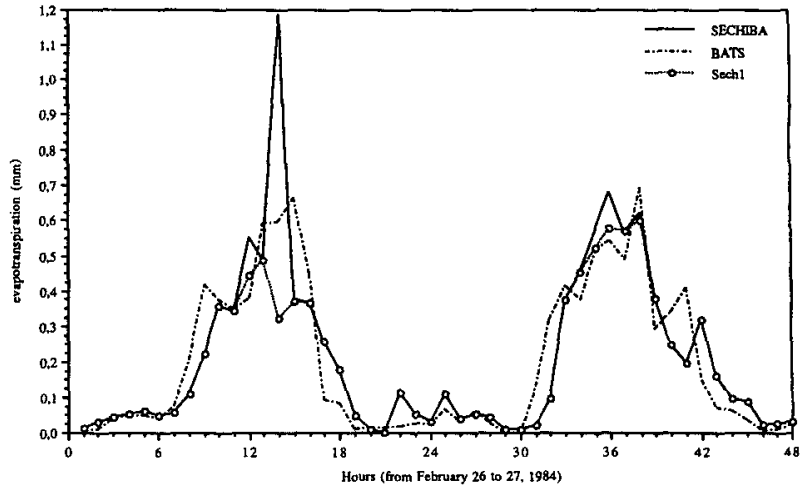

FIG. 15b. Hourly rates of total evapotranspiration ( $\mathrm{mm}$ ) simulated in SECHIBA, in BATS, and in Sech1. The days considered are 26 and 27 February 1984. In Sech 1 canopy transpiration is prevented from taking over interception loss within the same time step.

States, in western Europe, Siberia, southern Asia, equatorial Africa, and South America.

The very straightforward effect of such a decrease in total evapotranspiration is an increase in the simulated soil temperature. This in turn leads to drastic changes of the continental thermal low pressure cells, the intensity of which is much lower in CLAS1 than in CLAS (Figs. 18b-c). Over North America the differences obtained between our simulations are larger than $2 \mathrm{hPa}$; they exceed $4 \mathrm{hPa}$ over western Europe. The pressure gradient between continents and oceans is enhanced when vegetation is removed, thereby inducing stronger winds at the ocean / land edges in the ITCZ, along the American shores, and in middle and high southern latitudes. We indeed simulate an intensification of African and Asian monsoons. In most of the areas where precipitated water mainly comes from oceanic advection, rainfall is increased. Where it comes from local evapotranspiration (forests in eastern Europe, for example), the deforestation-induced decrease in latent heat flux leads to a decrease in the precipitation rate.

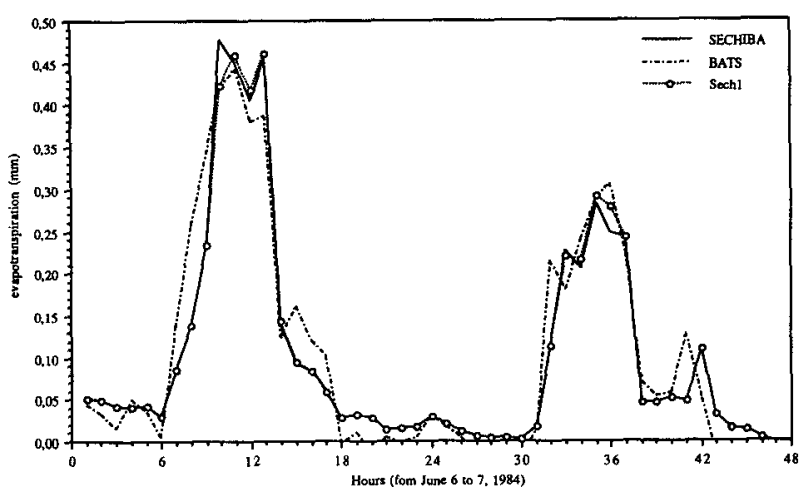

FIG. 15c. Hourly rates of total evapotranspiration (mm) simulated in SECHIBA, in BATS, and in Sech 1. The days considered are 6-7 June 1984. In Sech 1 canopy transpiration is prevented from taking over interception loss within the same time step. 

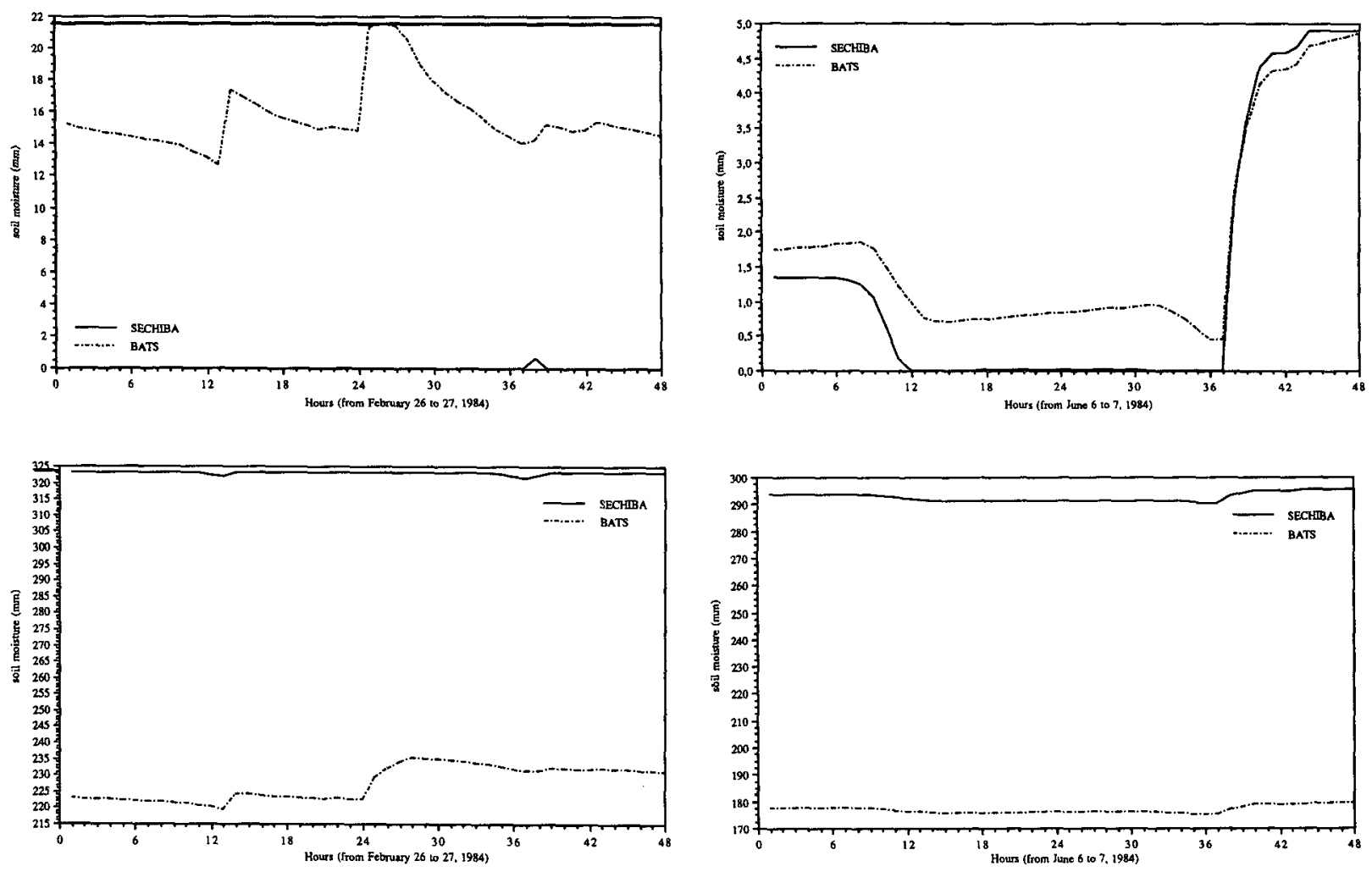

FIG. 16. Hourly values of (a) the upper soil layer water content (mm) and (b) the root zone water content (mm) simulated in SECHIBA and in BATS. The days considered are 26 and 27 February 1984. (c) and (d) as in (a) and (b) but for 6 and 7 June 1984.

On the other hand, evaporation has increased in the arid and semiarid regions of the Northern Hemisphere. Over the Sahara, south Argentina, and the southwestern part of Africa, the wind patterns are such that water vapor is advected from the ocean. It is the reinforcement in the simulated speed of these winds in CLAS1 that leads to more precipitation and, therefore, to larger rates of evaporation.

The effects of overgrazing all land areas can be compared to the results obtained by Shukla and Mintz (1982), who analyzed the influence of preventing

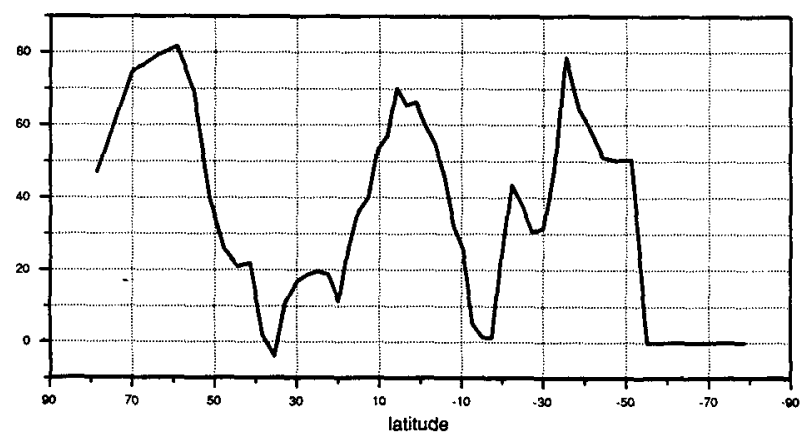

FIG. 17. Difference, zonally averaged, in the total soil-water content initialization $(\mathrm{mm}$ ) between the simulations CLAS and CLAS2. evaporation from land on the climate simulated by an AGCM. They have also shown that the heating of continents produced the development of thermal lows, and their effect was more important than ours since the reduction of evapotranspiration they prescribed was stronger than the one we simulate in CLAS1. They have also obtained, as a consequence, a general decrease of precipitation over land, except in the ITCZ where they simulated an intensification of Indian rainfall, while no change was obtained over the northern part of South America. This is quite similar to our results. Both sensitivity experiments illustrate the difference in rainfall response between small-scale and large-scale areas. In the case of large-scale areas, the variations of rainfall are not only influenced by the local change in evapotranspiration, but also by a possible variation in the humidity convergence that depends on the largescale circulation.

We can also point out that the deforestation experiments conducted with AGCMs over tropical regions seem to give different conclusions (Dickinson and Henderson-Sellers 1988; Lean and Warrilow 1989; Polcher and Laval 1992; Shukla et al. 1990). In this case the effect is more complex because the change in vegetal cover is associated not only with a variation of surface resistance, but also with larger aerodynamic resistance and albedo. 


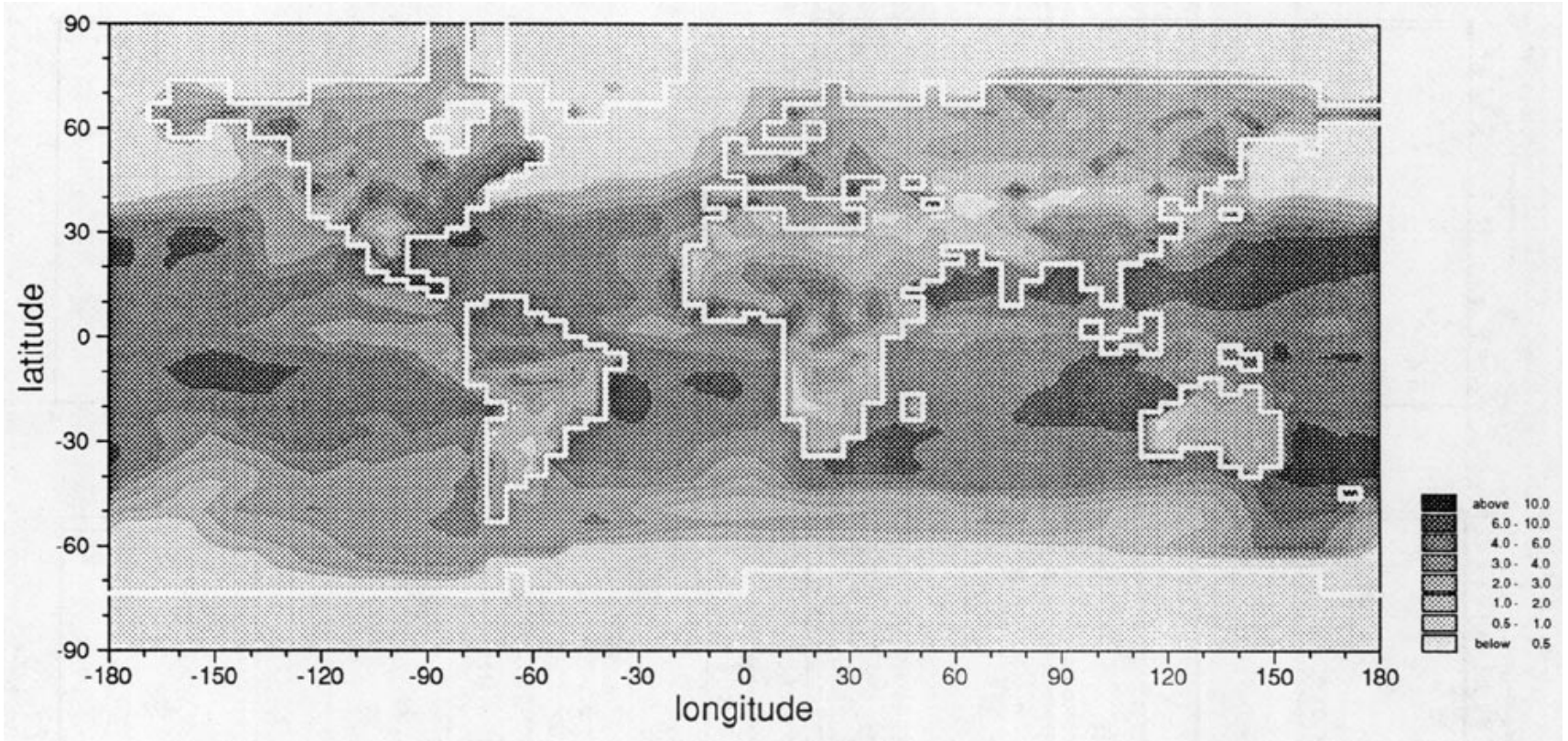

FIG. 18a. Total evapotranspiration rate $\left(\mathrm{mm} \mathrm{day}^{-1}\right)$ simulated in CLAS1 and averaged over July. In CLAS1 vegetation at all land points is replaced by bare ground.

\section{b. Changing the initial soil moisture content}

The zonal differences in initial soil water content are displayed in Fig. 17. There are three main latitudinal bands where these differences are very large: the equatorial regions $\left(10^{\circ} \mathrm{S}\right.$ to $\left.10^{\circ} \mathrm{N}\right)$, the middle / high northern latitudes $\left(50^{\circ}\right.$ to $\left.70^{\circ} \mathrm{N}\right)$, and the subtropical areas of the Southern Hemisphere $\left(30^{\circ}\right.$ to $\left.50^{\circ} \mathrm{S}\right)$.
The zonal distributions of soil moisture simulated in CLAS and CLAS2, averaged over July, are displayed in Fig. 19. At all latitudes the aforementioned differences have diminished (especially in the equatorial belt and in the southern latitudes). It seems that the coupled model is forgetting its initial state. When we start with a drier soil, the surface relative humidity is smaller, thereby limiting the gradient of specific humidity be-

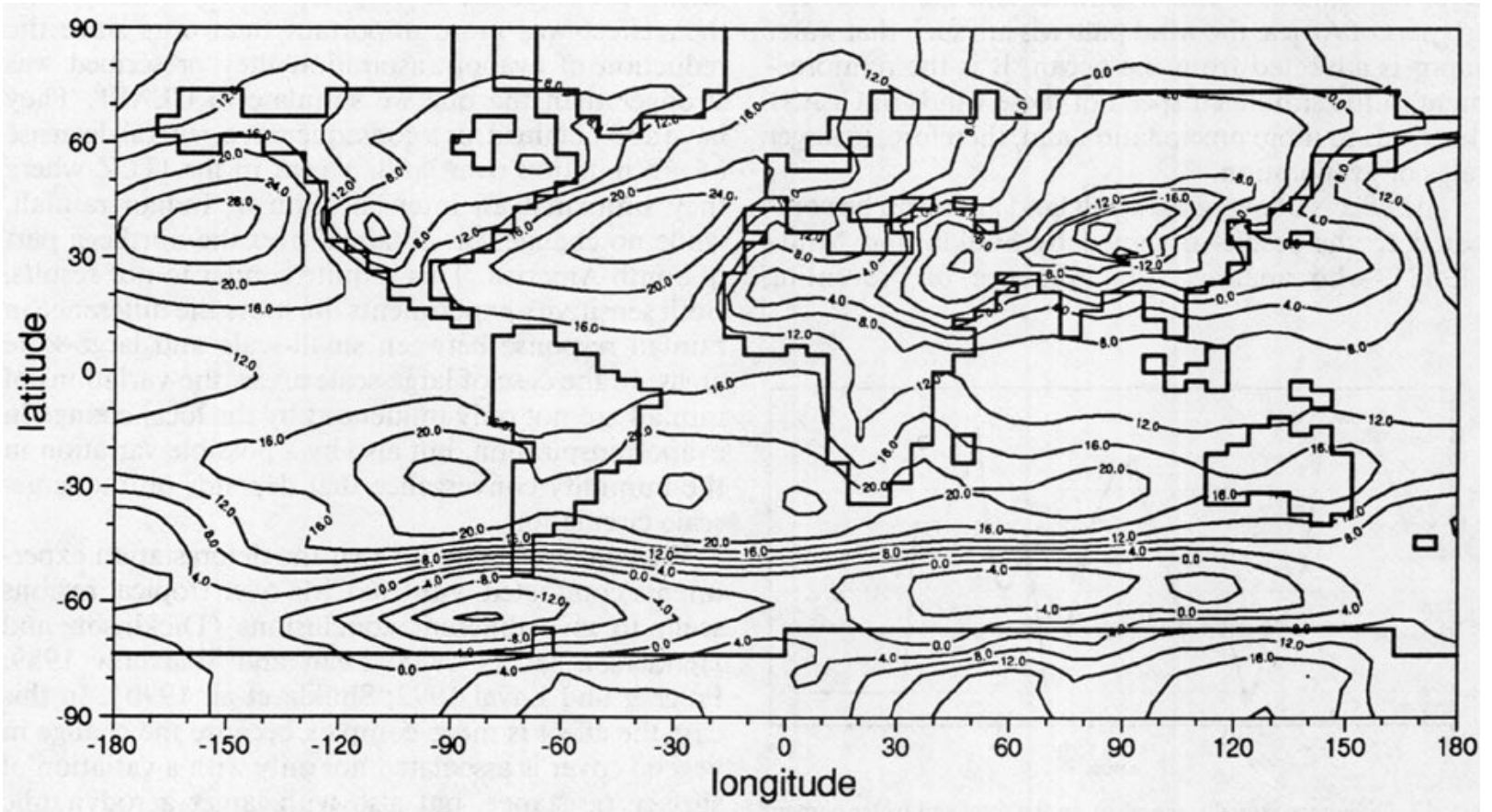

FIG. 18b. Sea level pressure (hPa) simulated in CLAS and averaged over July. 


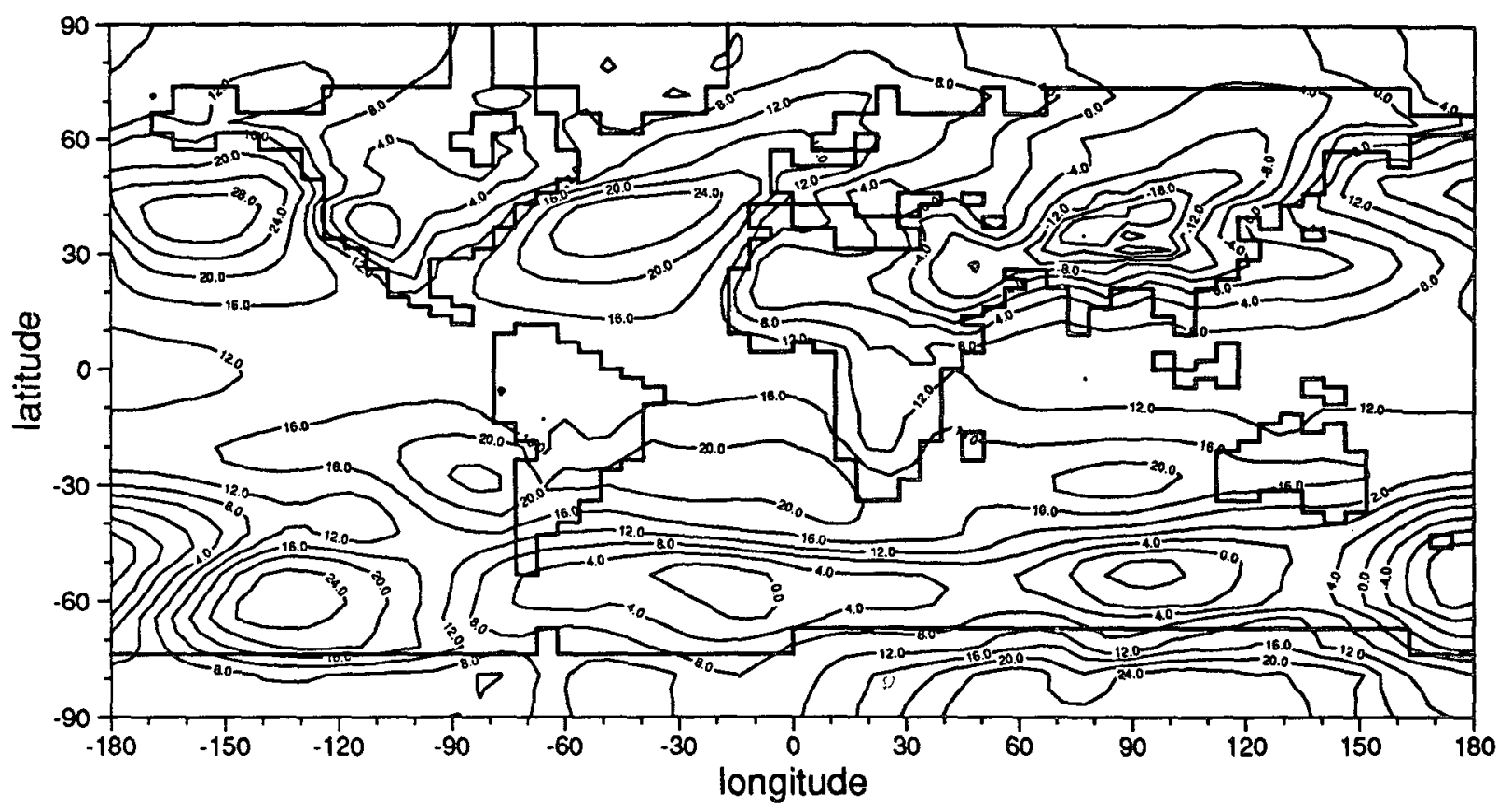

FIG. $18 \mathrm{c}$. Sea level pressure ( $\mathrm{hPa}$ ) simulated in CLASI and averaged over July.

In CLAS1 vegetation at all land points is replaced by bare ground.

tween the surface and the overlying air. Canopy transpiration and soil evaporation are then weaker in CLAS2 than in CLAS, and since we simulate equivalent rates of precipitation (even slightly larger in CLAS2 in some regions), the soil can fill up quicker in the former.

In the Northern Hemisphere, however, the differences remain very important $(\sim 50 \mathrm{~mm})$. As noted previously $(\S 4 \mathrm{c})$ these latitudes are experiencing a drying of their soil at that time of year, the rates of evapotranspiration being larger than those of precipitation. Since $E_{\mathrm{tr}}$ and $E_{g}$ are decreasing with the available water decrease in soil and the soil moisture is not being restored, it takes more time for the initial discrepancies to vanish.

The other consequences of the change in initial soil water content that we have obtained, apart from lowering the evapotranspiration rates, are 1) higher temperatures of the soil surface and lower troposphere, 2) a general decrease in sea level pressure over the continents, 3) no change in intensity of the oceanic anticyclones but a reduced extension toward the continents, 4) stronger temperature and pressure gradients between sea and land, followed by 5 ) the enhancement of wind speed in the monsoon regions.

These results are very similar to the ones obtained by Hui (1989) and Serafini (1986), even though they have used different versions of the LMD AGCM.

We carried out this same sensitivity experiment but with a bare land, as in CLAS1. The results showed that the model forgets its initial soil moisture distribution more rapidly in this case. The reason for this is that the soil resistance increases very quickly with a decreasing relative soil moisture, thereby preventing water from evaporating. Since the simulated precipitation rates are not very different in both experiments, the restoration of soil moisture is faster. When vegetation is present, its roots can extract water at greater depths in the soil, and therefore, the total latent heat flux is larger than in the bare-land case.

\section{c. Preventing the canopy from intercepting rainfall}

When the foliage is prevented from intercepting precipitation and dew, canopy evapotranspiration can only occur in the form of transpiration. Under the same atmospheric and soil moisture conditions, observed during the first time steps of the integration, the simulated latent heat flux is then smaller in CLAS3 than

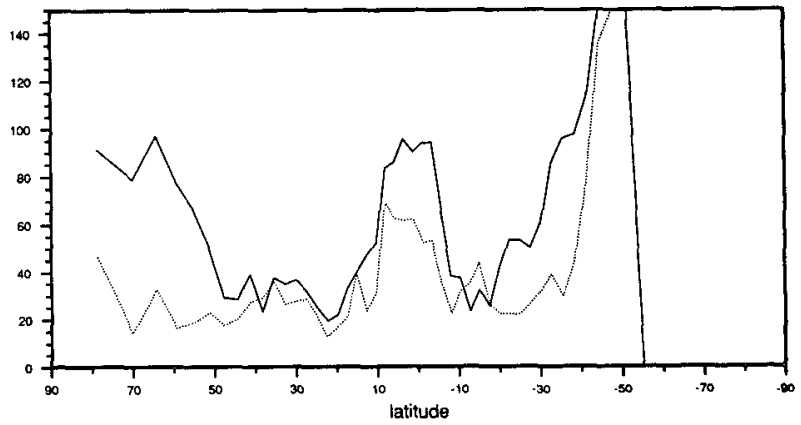

FIG. 19. Total soil water content $(\mathrm{mm})$ simulated in CLAS (plain line) and in CLAS2 (dashed line), averaged over July and zonally averaged. In CLAS2 the initial total soil moisture is modified. 
in CLAS. Indeed, canopy transpiration involves the canopy and the architectural resistances as well as the surface relative humidity, while the only resistance opposing interception loss is architectural.

The monthly differences in zonally averaged evapotranspiration rate are displayed in Fig. 20 together with the interception loss simulated in CLAS. The former is much smaller than the latter, bringing forward the fact that $E_{\mathrm{tr}}$ partly compensates for the "missing" $E_{i}$. The largest differences are quite small $(\sim 0.5 \mathrm{~mm}$ day $^{-1}$ ) and are observed where interception loss is the most important, that is, in the forested areas of the northern latitudes $\left(50^{\circ}\right.$ to $\left.70^{\circ} \mathrm{N}\right)$ and in the intertropical convergence zone where rainfall is abundant and $E_{i}$ is a major component of canopy evapotranspiration.

We have not found any clear change in other simulated variables such as precipitation, soil temperature, sea level pressure, wind speed, etc. But, since $E_{a}$ is smaller in CLAS3 than in CLAS while rainfall remains the same, the soil is more moist in the former. Differences do not exceed $15 \mathrm{~mm}$ however.

These results, although showing a relatively small sensitivity of the total evapotranspiration simulated to the water storage capacity of the foliage, do not imply that interception is an unimportant process to account for in such models: it only points out that, at the present stage of both the LMD AGCM and SECHIBA, parameterizations of interception and precipitation might not be compatible. Sato et al. (1989) made this statement clear that, whatever the cause (variability in topography or relatively small-scale convective cells), subgrid-scale variability in precipitation rate will affect the time and space average of rainfall interception and its evaporation. In the case of convective rainfall regimes, for example, local precipitation is usually large compared to the water storage capacity of the canopy, and the coupled model will underestimate rainfall infiltration into the soil.

\section{Summary and conclusions}

In this paper, parameterizations of the hydrologic exchanges between the soil-vegetation system and the

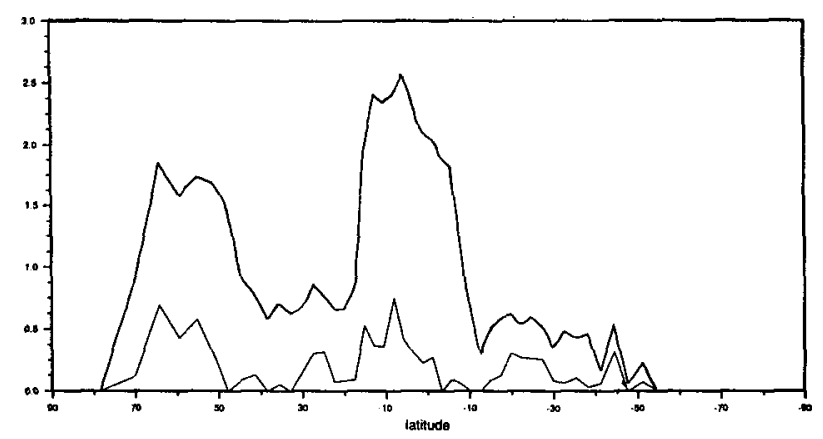

FIG. 20. Difference, averaged over July and zonally averaged, between the total evapotranspiration rates $\left(\mathrm{mm} \mathrm{day}^{-1}\right.$; lower line) simulated in CLAS and in CLAS3, together with the rates of interception loss $\left(\mathrm{mm} \mathrm{day}^{-1}\right.$; upper line) simulated in CLAS. In CLAS3 the foliage is prevented from intercepting rainfall and dew. atmosphere have been developed: evaporation, transpiration, interception loss, and storage. We have introduced (i) a canopy resistance and an architectural resistance to take into account the transfer between plants, the air around the leaves, and the reference level in the atmosphere, and (ii) a soil resistance for the transfer between soil and the atmosphere. This model, conceptually very simple, gives an annual variation of evapotranspiration over Amazonia, which agrees with the estimations made by Shuttleworth (1988).

This model has been implemented in our AGCM for climate studies. Each grid box has a fractional area of eight land cover types (from bare soil to rainforest) according to Matthews' (1983a,b; 1984) data, and the calculations of hydrologic exchanges are performed for each class, the average being made after taking into account the area sheltered by each type of cover. The distribution of evapotranspiration simulated by a July experiment is shown, and the high values obtained over regions where the foliage cover is important are quite comparable to the ones simulated with the coupled model NMC AGCM-SiB (Sato et al. 1989).

This approach is certainly much simpler than the SiB model (Sellers et al. 1986) or BATS (Dickinson et al. 1986), or even the SSiB (Xue et al. 1991). Its advantage is to define the parameters (as surface resistance, leaf area index, etc) that characterize each one of the eight land cover types, wherever they are found over the earth's surface. It is then the latent heat computed for each class that is averaged and not the parameters themselves. This parameterization has been used to study the impact of deforestation on climate (Polcher and Laval 1992). The next step will be to introduce more complexity: subgrid variability of rainfall and moisture, a dependence of the architectural resistance on the vertical structure of foliage, the relation between leaf area index and temperature, for example. It is certainly a major challenge in climate studies to be realistic in computing the transfers between land covers and the atmosphere with the resolutions used in AGCMs.

Acknowledgments. The authors are very grateful to Remi Buttel for providing the most updated version of the LMD AGCM, as well as software to analyze the results of our simulations. We would also like to thank the centre de Calcul vectoriel pour la Recherche for providing the computing power need.

Comparisons between SECHIBA and BATS were performed while the first author, Nathalie Ducoudré, was a postdoctoral candidate at the Jet Propulsion Laboratory (Pasadena, California). She warmly thanks Dr. Robert E. Dickinson for providing her with one of the latest versions of his Biosphere-Atmosphere Transfer Scheme (version 1e), and for his very helpful comments on this work. The authors also appreciated the very constructive comments and criticisms two anonymous reviewers made on an earlier version of the manuscript. 


\section{APPENDIX A}

$\Delta q_{i}$

\section{Bucket Formulations}

Total evapotranspiration $\left(E_{a}\right)$ is proportional to the potential rate $\left(E_{p}\right)$. The coefficient of proportionality $(\beta)$ is a function of total soil moisture $\left(W_{l}\right)$ and is known as the "aridity coefficient:"

$$
\begin{aligned}
& E_{a}=\beta E_{p} \\
& \beta=\begin{array}{ll}
1, & \text { if } \quad W_{t}>W_{c} \\
\frac{W_{t}}{W_{c}}, & \text { if } \quad W_{t} \leqslant W_{c} .
\end{array}
\end{aligned}
$$

Here, $W_{c}$ is the critical amount of soil moisture [half the value at saturation $\left.\left(W_{t \max }\right)\right]$ above which we assume evapotranspiration to take place at the potential rate, a function of the gradient of specific humidity between the surface and the overlying air:

$$
E_{p}=\rho \frac{q_{\mathrm{sat}}\left(T_{g}\right)-q_{a}}{r_{a}},
$$

where $r_{a}$ is the aerodynamic resistance calculated as in SECHIBA.

Water in the soil is held in only one reservoir, the root zone, which is filled from bottom to top by precipitation and emptied from top to bottom by evaporation. This is why it is called "bucket." Runoff occurs only when the soil is saturated, that is, when $W_{t}$ equals $W_{t \text { max }}$.

\section{APPENDIX B}

\section{Mathematical Symbols}

$a$

Parameter entering the calculation of canopy resistance. It is part of the function of water vapor concentration deficit $\left(\mathrm{kg} \mathrm{m}^{-3}\right)$.

$c \quad$ Empirical constant entering the calculation of surface relative humidity.

$c_{p} \quad$ Specific heat at constant pressure $\left(\mathrm{J} \mathrm{kg}^{-1} \cdot \mathrm{K}^{-1}\right)$.

$\delta c \quad$ Water vapor concentration deficit $\left(\mathrm{kg} \mathrm{m}^{-3}\right)$.

$f \quad$ Fraction of the water uptaken from the upper soil layer for canopy transpiration in BATS.

$h_{g} \quad$ Surface relative humidity.

$k_{0} \quad$ Parameter entering the calculation of canopy resistance. It is part of the function of water vapor concentration deficit $\left(\mathrm{kg} \mathrm{m}^{-2} \mathrm{~s}^{-1}\right)$.

$q_{\text {sat }}(T)$ Saturated specific humidity calculated at temperature $T$.

$q_{a} \quad$ Specific humidity of the air at the reference level chosen in the atmosphere.

$\Delta q_{g} \quad$ Gradient of specific humidity between the ground and the overlying air. $r_{a}$

$r_{a c}$

$\Delta q_{s}$

$\Delta q_{\mathrm{tr}}$

$r_{a g}$

$r_{a g}$

$r_{c}$

$r_{\text {la }}$

$r_{g}$

$r_{\text {soil }}$

$r_{0}$

$t$

C

$C_{d}$

$D_{r}$

$D_{t}$

$D_{u}$

$E_{a}$

$E_{g}$

$E_{g \max }$

$E_{i}$

$E_{p}$

$E_{s}$
Gradient of specific humidity between the water stored on foliage and the overlying air.

Gradient of specific humidity between the snow covering the ground and the overlying air.

Gradient of specific humidity between the inside of stomata and the air overlying the leaves.

Aerodynamic resistance, opposing the transfers of water vapor between the surface and the air at the reference level chosen in the atmosphere $\left(\mathrm{s} \mathrm{m}^{-1}\right)$.

Surface aerodynamic resistance calculated in BATS. It opposes the transfers of water vapor between the soil surface and the air within foliage in the vegetated part of the grid box $\left(\mathrm{s} \mathrm{m}^{-1}\right)$.

Surface aerodynamic resistance calculated in BATS. It opposes the transfers of water vapor between the soil surface and the overlying air in the clearing part of the grid box $\left(\mathrm{s} \mathrm{m}^{-1}\right)$.

Canopy resistance, opposing the transfers of water vapor between the inside of stomata and the air overlying the leaves $\left(\mathrm{s} \mathrm{m}^{-1}\right)$.

Leaf aerodynamic resistance calculated in BATS. It opposes the transfers of water vapor between the surface of the leaves and the air within foliage $\left(\mathrm{s} \mathrm{m}^{-1}\right)$.

Soil resistance, opposing the transfers of water vapor between the soil and the overlying air $\left(\mathrm{s} \mathrm{m}^{-1}\right)$.

Soil resistance of a 1-m depth of dry soil. It opposes the evaporation of the water located below $1 \mathrm{~m}\left(\mathrm{~s} \mathrm{~m}^{-1}\right)$.

Architectural resistance, opposing the transfers of water vapor, within the foliage, between the leaves and the top of the canopy $\left(\mathrm{s} \mathrm{m}^{-1}\right)$.

Time (s).

Bulk heat capacity of the surface soil layer (cal cm ${ }^{-2} \mathrm{~K}^{-1}$ ).

Surface drag coefficient.

Depth of the root zone in BATS ( $\mathrm{mm})$.

Depth of the total soil $(\mathrm{mm})$.

Depth of the upper soil layer $(\mathrm{mm})$.

Total evapotranspiration rate $\left(\mathrm{mm} \mathrm{s}^{-1}\right)$.

Soil evaporation $\left(\mathrm{mm} \mathrm{s}^{-1}\right)$.

Maximum soil evaporation, that is, maximum sustainable diffusive flux of water through the soil-air interface in BATS $\left(\mathrm{mm} \mathrm{s}^{-1}\right)$.

Evaporation of water intercepted by the foliage $\left(\mathrm{mm} \mathrm{s}^{-1}\right)$.

Potential evaporation calculated in the Bucket model $\left(\mathrm{mm} \mathrm{s}^{-1}\right)$.

Snow sublimation $\left(\mathrm{mm} \mathrm{s}^{-1}\right)$.

Canopy transpiration $\left(\mathrm{mm} \mathrm{s}^{-1}\right)$. 
$G_{n} \quad$ Gravitational drainage at the root zone-recharge layer interface in BATS $\left(\mathrm{mm} \mathrm{s}^{-1}\right)$.

$G_{u r} \quad$ Gravitational drainage at the upper soil layerroot zone interface in BATS $\left(\mathrm{mm} \mathrm{s}^{-1}\right)$.

$H_{s} \quad$ Total sensible heat flux $\left(\mathrm{mm} \mathrm{s}^{-1}\right)$.

$L \quad$ Latent heat for the vaporization of water $\left(\mathrm{J} \mathrm{kg}^{-1}\right)$.

LAI Single-sided leaf area index.

$P_{s} \quad$ Surface pressure (hPa).

$p_{r} \quad$ Incident precipitation rate $\left(\mathrm{mm} \mathrm{s}^{-1}\right)$.

$R_{b} \quad$ Subsurface soil runoff in BATS $\left(\mathrm{mm} \mathrm{s}^{-1}\right)$.

$R_{c} \quad$ Foliage runoff, that is, excess of water intercepted $\left(\mathrm{mm} \mathrm{s}^{-1}\right)$.

$R_{n} \quad$ Surface net radiation $\left(\mathrm{W} \mathrm{m}^{-2}\right)$.

$R_{s} \quad$ Incident solar radiation at the land surface $\left(\mathrm{W} \mathrm{m}^{-2}\right)$.

$R_{s u} \quad$ Surface soil runoff in BATS $\left(\mathrm{mm} \mathrm{s}^{-1}\right)$.

$R_{t} \quad$ Total soil runoff $\left(\mathrm{mm} \mathrm{s}^{-1}\right)$.

$R_{s 0} \quad$ Parameter entering the calculation of canopy resistance. It is the half-light saturation factor, a part of the function of incident solar radiation $\left(\mathrm{W} \mathrm{m}^{-2}\right)$.

$S_{n} \quad$ Depth of snow covering the land surface (equivalent $\mathrm{mm}$ of water).

$S_{\mathrm{cr}} \quad$ Critical depth of snow above which the entire grid box is considered to be covered by snow (equivalent $\mathrm{mm}$ of water).

$T_{c} \quad$ Foliage temperature calculated in BATS (K).

$T_{g} \quad$ Soil surface temperature (K).

$T_{r \max } \quad$ Maximum sustainable transpiration rate in BATS $\left(\mathrm{mm} \mathrm{s}^{-1}\right)$.

$V_{a} \quad$ Wind speed at the reference level chosen above canopy $\left(\mathrm{m} \mathrm{s}^{-1}\right)$.

$W_{c} \quad$ Critical amount of soil water content above which, in the Bucket model, evapotranspiration takes place at the potential rate $(\mathrm{mm})$.

$W_{\text {dew }} \quad$ Amount of water intercepted by the foliage $(\mathrm{mm})$.

$W_{d \max } \quad$ Maximum amount of water the foliage can intercept during a rainfall event $(\mathrm{mm})$.

$W_{d} \quad$ Water content of the deep soil layer $(\mathrm{mm}$; $=W_{l}-W_{u}$ ).

$W_{r} \quad$ Water content of the root zone in BATS $(\mathrm{mm})$.

$W_{t} \quad$ Water content of the total depth of soil considered $(\mathrm{mm})$.

$W_{t \max } \quad$ Maximum amount of water the total depth of soil considered can hold $(\mathrm{mm})$.

$W_{u} \quad$ Water content of the upper soil layer $(\mathrm{mm})$.

$W_{u \max } \quad$ Maximum amount of water the upper soil layer can hold ( $\mathrm{mm})$.

$\alpha_{g} \quad$ Fraction of the grid box experiencing soil evaporation.

$\alpha_{i} \quad$ Fraction of the grid box experiencing canopy interception loss.

$\alpha_{s} \quad$ Fraction of the grid box experiencing snow sublimation. $\alpha_{\mathrm{tr}}$

$\beta$

$\gamma_{n}$

$\gamma_{u r}$

$\sigma_{f}$

$\lambda$

$\rho$

Abramopoulos, F., C. Rosenzweig, and B. Choudhury, 1988: Improved ground hydrology calculations for global climate models (GCMs): Soil water movement and evapotranspiration. J. Climate, 1, 921-941.

André, J.-C., and C. Blondin, 1986: On the effective roughness length for use in numerical three-dimensional models. Bound-Layer Meteor., 35, 231-245.

Avissar, R., and M. M. Verstraete, 1990: The representation of continental surface processes in atmospheric models. Rev. Geophys., 28, 35-52.

Bartman, F. L., 1980: A time variable model of Earth's albedo. NASA Contract Report 159259, NASA Grant MSG, 1482, University of Michigan.

Blondin, C., 1988: Research on land surface parameterization scheme at ECMWF. Parameterization of Fluxes over Land Surface, ECMWF, 285-330.

Choisnel, E., 1977: Le bilan d'énergie et le bilan hydrique du sol. La Météorologie, VI, 11, 103-133.

__ 1984: Un Modèle agrométéorologique opérationnel de bilan hydrique utilisant des données climatiques. Les besoins en eau des cultures, Proc. Conférence internationale CIID, Paris.

Deardorff, J. W., 1978: Efficient prediction of ground surface temperature and moisture, with inclusion of a layer of vegetation. J. Geophys. Res., 83, 1889-1903.

Dickinson, R. E., 1984: Modeling evapotranspiration for three-dimensional global climate models. Climate Processes and Climate Sensitivity, Geophys. Monogr. No. 29, Maurice Ewing Volume, Amer. Geophys. Union, 58-72.

-, and A. Henderson-Sellers, 1988: Modelling tropical deforestation: A study of GCM land surface parameterizations. Quart. J. Roy. Meteor. Soc., 114, 439-462.

- - - P. J. Kennedy, and M. F. Wilson, 1986: BiosphereAtmosphere Transfer Scheme (BATS) for the NCAR Community Climate Model. Technical Note, NCAR/TN-275+STR, National Center for Atmospheric Research, 69 pp.

Ducoudré, N. I., 1990: Sensibilité du climat simulé à la paramétrisation des échanges de vapeur d'eau entre la Biosphère et l'Atmosphère. Thèse de Doctorat, Université de Paris VI, 440 pp.

- , and R. E. Dickinson, 1991: Comparing two formulations of the hydrologic exchanges at the Biosphere/Atmosphere interface, developed for use within AGCMs. A micrometeorological study over Manaus (Brazil). Atelier de Modélisation de l'Atmosphère, Climat et Atmosphère à Grande Echelle, Toulouse, France.

Entekhabi, D., and P. S. Eagleson, 1989: Land surface hydrology parameterization for atmospheric general circulation models including subgrid-scale spatial variability. J. Climate, 2, 816-831.

Fouquart, Y., and B. Bonnel, 1980: Computations of solar heating of the Earth's atmosphere: A new parameterization. Contrib. Atmos. Phys., 53.

Halldin, S., B. Saugier, and J. Y. Pontailler, 1985: Evapotranspiration of a deciduous forest: Simulation using routine meteorological data. J. Hydrol., 75, 323-341.

Huber, L., 1987: Modélisation spatio-temporelle de la durée d'hu- 
mectation d'un couvert végétal après une pluie. Thèse de Docteur-Ingénieur, INRA, $155 \mathrm{pp}$.

Hui, D., 1989: Etudes du climat simulé par le modèle de circulation générale du LMD avec différentes représentations de l'humidité du sol. Thèse de Doctorat, Université de Paris VI, $250 \mathrm{pp}$.

Jaëger, L., 1983: Monthly and areal patterns of mean global precipitation. Variations in the Global Water Budget, D. Reidel, 129140 .

Jarvis, P. G., 1976: The interpretation of the variations in leaf water potential and stomatal conductance found in canopies in the fields. Phil. Trans. Roy. Soc. London, Ser. B, 273, 593-610.

Katayama, A., 1972: A simplified scheme for computing radiative transfer in the troposphere. Tech. Rep. No. 6, Department of Meteorology, UCLA, 77 pp.

Kuo, H. L., 1965: On formation and intensification of tropical cyclones through latent heat release by cumulus convection. $J$. Atmos. Sci., 22, 40-63.

Laval, K., 1988: Experience with surface processes at LMD. Parameterization of Fluxes Over Land Surface, ECMWF, 171-205 pp.

- , and L. Picon, 1986: Effect of a change of surface albedo of the Sahel on climate. J. Atmos. Sci., 43, 2418-2429.

Le Treut, H., and K. Laval, 1984: The importance of cloud radiation interaction for the simulation of climate. New Perspectives in Climate Modelling. A. Berger, Ed., Elsevier, 199-222.

Lean, J., and D. A. Warrilow, 1989: Simulation of the regional impact of Amazon deforestation. Nature, 342, 411-413.

Lohammar, T., S. Larsson, S. Linder, and S. O. Falk, 1980: Simulation models of gaseous exchange in Scotch pine. Structure and Function of Northern Coniferous Forest, Ecol. Bull. 32, 505-523.

Mahfouf, J.-F., and J. Noilhan, 1991: Comparative study of various formulations of evaporation from bare soil using in-situ data. J. Appl. Meteor., 30, 1354-1365.

Manabe, S., and R. F. Strickler, 1964: Thermal equilibrium of the atmosphere with a convective adjustment. J. Atmos. Sci., 21, $361-385$.

Mason, P. J., 1988: The formation of areally-averaged roughness lengths. Quart. J. R. Meteor. Soc., 114, 399-420.

Matthews, E., 1983a: Prescription of land surface boundary conditions in GISS GCM II: A simple method based on high-resolution vegetation databases. Tech. Memo. 86096, NASA, 20 pp.

- $1983 \mathrm{~b}$ : Global vegetation and land use: New high resolution databases for climate studies. J. Climate Appl. Meteor., 22, 474487.

-, 1984: Vegetation land use and seasonal albedo datasets: Documentation of archived tape. Tech. Memo. 86107, NASA, 12 $\mathrm{pp}$.

McNaughton, K. G., 1987: Comments on "Modeling the effects of vegetation on climate." Geophysiology of Amazonia, R. E. Dickinson, Ed., Wiley \& Sons, 526 pp.

- , and P. G. Jarvis, 1991: Effects of the spatial scale on stomatal control of transpiration. Agric. Forest Meteor., 54, 279-301.

Mintz, Y., 1982: Influence of the vegetation structure on the thermal forcing of the atmosphere. JCS Study Conf. on the Physical Basis for Climate Prediction on Seasonal Annual and Decadal Time Scales, Leningrad, $11 \mathrm{pp}$.

- 1984: The sensitivity of numerically simulated climates to landsurface boundary conditions. The Global Climate, J. T. Houghton, Ed., Cambridge University Press, 79-105.

- - and Y. V. Serafini, 1992: Global monthly climatology of soil moisture and water balance. Clim. Dyn., 8, 13-27.

Monteith, J. L., 1963: Gas exchange in plant communities. Environmental Control of Plant Growth, L. T. Evans, Ed., Academic Press, 95-112.
Noilhan, J., and S. Planton, 1989: A simple parameterization of landsurface processes for meteorological models. Mon. Wea. Rev., 117, 536-549.

Oltman, R. E., H. O. R. Sternbert, F. C. Ames, and L. C. Davis, 1964: Amazon River investigations reconnaissance measurements of July. U.S. Geol. Surv. Circ., 486, 1-15.

Perrier, A., 1975: Etude physique de l'évapotranspiration dans les conditions naturelles. Ann. Agron., 26, 1-18, 105-123, 229-243.

Polcher, J., and K. Laval, 1992: The impact of African and Amazonian deforestation on tropical climate. J. Hydrol., in press.

Rutter, A. J., 1975: The hydrological cycle in vegetation. Vegetation and the Atmosphere, J. L. Monteith, Ed., Academic Press, 111 154.

Sadourny, R., and K. Laval, 1984: January and July performances of the LMD general circulation model. New Perspectives in Climate Modeling, A. Berger, Ed., Elsevier, 173-198.

Sasamori, T., 1968: The radiative cooling calculation for application to general circulation experiments. J. Appl. Meteor., 7, 721729.

Sato, N., P. J. Sellers, D. A. Randall, E. K. Schneider J. Shukla, J. L. Kinter, III, Y.-T. Hou, and E. Albertazzi, 1989: Effects of implementing the Simple Biosphere model in a general circulation model. J. Atmos. Sci., 46, 2757-2782.

Saugier, B., and N. Katerji, 1991: Some plant factors controlling evapotranspiration. Agric. Forest Meteor., 54, 263-277.

Sellers, P. J., Y. Mintz, Y. C. Sud, and A. Dalcher, 1986: A Simple Biosphere model $(\mathrm{SiB})$ for use within general circulation models. J. Atmos. Sci., 43, 505-531.

— W. J. Shuttleworth, and J. L. Dorman, 1989: Calibrating the Simple Biosphere model for Amazonian tropical forest using field and remote-sensing data. Part I: Average calibration with field data. J. Appl. Meteor., 28, 727-759.

Serafini, Y. V., 1986: Modélisation de l'interface sol-atmosphère en utilisant des données conventionnelles et satellitaires: Impact climatique à grande échelle. Thèse de Doctorat d'Etat, Université de Paris VI.

Shukla, J., and Y. Mintz, 1982: Influence of land surface evapotranspiration on the Earth's climate. Science, 215, 1498-1501.

_ J. C. Nobre, and P. J. Sellers, 1990: Amazon deforestation and climate change. Science, 247, 1322-1325.

Shuttleworth, W. J., 1988: Evaporation from Amazonian rainforest. Proc. R. Soc. London, B., 233, 321-346.

—_, J. H. C. Gash, C. R. Lloyd, C. J. Moore, J. Roberts, A. D. O. Marques, G. Fisch, V. D. P. Silva, M. N. G. Ribeiro, L. C. B. Molion, L. D. A. de Sa, J. C. Nobre, O. M. R. Cabral, S. R. Patel, and J. C. de Moraes, 1984a: Observations of radiation exchange above and below Amazonian forest. Quart. J. Roy. Meteor. Soc., 110, 1163-1169.

$-\longrightarrow,-,-,,-,-,-,-,-,-,-,-,-,-$, ments of energy partition for Amazonian forest. Quart. J. Roy. Meteor. Soc., 110, 1143-1162.

UNESCO, 1973: Classification internationale et cartographie de la végétation. Coll. Ecologie.

Warrilow, D. A., A. B. Sangster, and A. Slingo, 1986: Modelling of land surface processes and their influence on European climate: Dynamical climatology. Tech. Note, 38, Meteorological Office, Bracknell, 92 pp.

Wood, E. F., D. P. Lettenmaier, and V. G. Zartarian, 1992: A land surface hydrology parameterization with sungrid scale variability for general circulation models. J. Geophys. Res., 97, 2717-2728.

Xue, Y., P. J. Sellers, J. L. Kinter, and J. Shukla, 1991: A simplified biosphere model for global climate studies. J. Climate, 4, 345364. 